Peak Civil Technologies 2525 C Street, Suite 201

Anchorage, AK 99503 (907) 263-7071

FINAL REPORT: THE USE OF GEOFIBER AND SYNTHETIC FLUID FOR STABILIZING MARGINAL SOILS

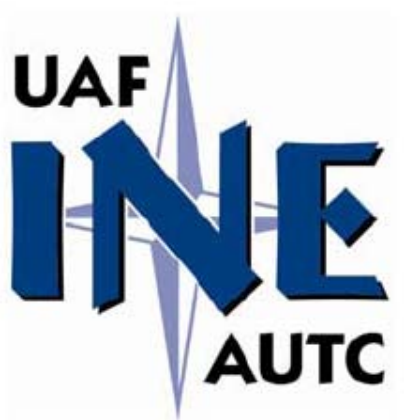

Prepared by:

Kenan Hazirbaba, Ph.D.

Billy Connor, P.E.

Duane Davis Yu Zhang

University of Alaska Fairbanks Fairbanks, AK 99775 (907) 474-7497

INE Project Number: RR07.03 1 October 2007 


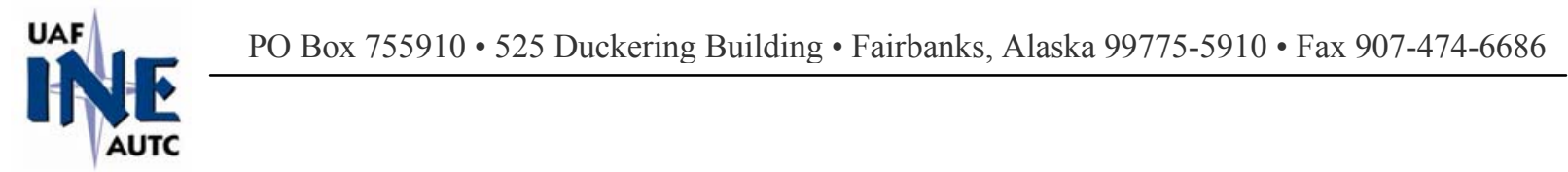

October 1, 2007

Final Draft Report:

The Use of Geofiber and Synthetic Fluid

for Stabilizing Marginal Soils

Attention: Mr. Dave Brangan, General Manager

Dear Mr. Brangan:

We are pleased to submit this draft final report on "Laboratory Evaluation of the Use of Geofiber and Synthetic Fluid for Stabilizing Marginal Soils" to Peak Civil Technologies (PCT). The proposal for this work was submitted to PCT on June 8, 2007. As described in this report, the work was completed in general conformance with the scope of that proposal.

The analyses supporting the conclusions provided in this report are based on the experimental data collected by my research team during the laboratory investigation. Our initial findings from this limited research indicated some promising results that may lead to significant improvement in marginal soils.

We at the Institute of Northern Engineering appreciate the opportunity to assist PCT on this project. We should be able to incorporate any comments you have into the final report document within a reasonable time frame. Please contact us if you have any questions or require additional information.

Sincerely,

Kenan Hazirbaba, Ph.D.

Assistant Professor

Billy Connor, P.E.

AUTC Director 


\title{
THE USE OF GEOFIBER AND SYNTHETIC FLUID FOR STABILIZING MARGINAL SOILS
}

\section{EXECUTIVE SUMMARY}

\begin{abstract}
Alaska University Transportation Center (AUTC) was approached by Peak Civil Technologies (PCT) for a collaborative research effort on a newly introduced soil stabilization technique that may be promising for transportation infrastructure projects in the North. The technique developed originally under the leadership of PCT utilizes a combination of two non-traditional stabilizer agents; geofibers and synthetic fluid. PCT has recently applied the technique in Cape Simpson, Alaska, with a poorly graded sand (USCS class: SP) and is now proposing to use it with silty sand (USCS class: SM) in Bethel, Alaska. "How effective will the use of geofibers and synthetic fluid become in improving the Bethel silty sand (SM)" is the question that this research project aims to answer through a systematic experimental study.
\end{abstract}

The bearing capacity and compressive strength of the soil before and after improvement were investigated. The improvement in bearing capacity of Bethel silty sand with additions of geofibers and synthetic fluid was studied through CBR tests, and the performance and strength characteristics were investigated through undrainedunconsolidated (UU) triaxial compression tests.

Evaluation of the Bethel silty sand, through CBR tests, showed marginal to significant improvement when stabilized by geofibers or combination of geofibers and synthetic fluid. The native soil at optimum moisture content, which was found to be about $11 \%$, displayed average CBR test values of 31 at 0.2 inch depth of penetration. This CBR value falls within the typical range (20-40) for SM type silty sand. Addition of $0.5 \%$ geofibers increased the CBR values to 62 at 0.2 inch depth of penetration and to much larger values at greater depths of penetration, indicating $100 \%$ or larger improvement. With these increased CBR values, the geofiber-reinforced soil fall within the range (60-80) for well-graded gravel or sandy gravel soils. Addition of the synthetic fluid alone did not provide a noticeable improvement in the CBR values. In general, the CBR values obtained from the soil samples improved with synthetic fluid were very similar to those obtained from unimproved native soil samples at optimum moisture content. However, aging soil samples by approximately 10 days resulted in significant 
improvement in the CBR values. The improvement in the CBR value with aging, for the combination of 5\%-synthetic fluid / 6\%-water / 0.5\%-geofibers was found to be on the order of $340 \%$; the CBR increased from 36 (in the case of a non-aged sample) to 124 (in the case of an aged sample).

In terms of soil-strength characteristics, the UU triaxial compression tests indicated a friction angle of $41.8^{\circ}$ and a slight cohesion of 2.9 psi for the native (no stabilizer added) soil samples compacted (Modified Proctor) at the optimum moisture content of $11 \%$. When $0.5 \%$ geofiber was added to the soil, the cohesion increased significantly, from 2.9 psi to $23.5 \mathrm{psi}$, while the friction angle increased by about $2^{\circ}$ only. However, the addition of synthetic fluid along with geofiber showed a less pronounced increase in cohesion with a more significant improvement in the friction angle. The cohesion and friction angle for this case were 11.2 psi and $53.6^{\circ}$, respectively.

Based on this limited laboratory effort, it is clear that the geofiber and synthetic fluid can significantly increase the bearing capacity and strength of the Bethel silty sand. However, to better evaluate the effectiveness of these stabilizing materials further research is recommended. 
Table of Contents

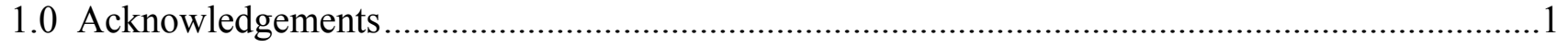

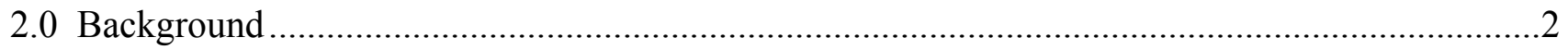

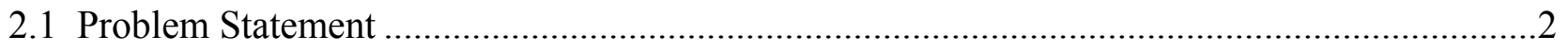

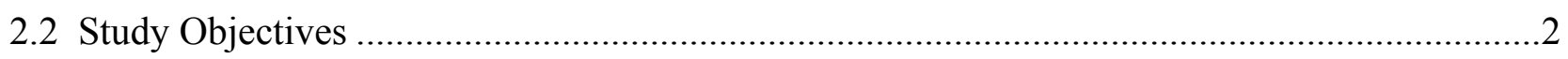

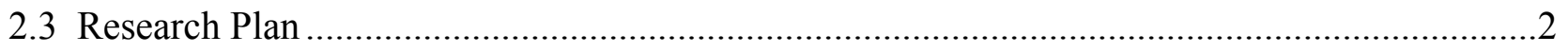

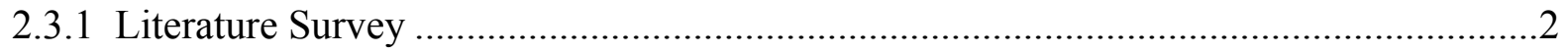

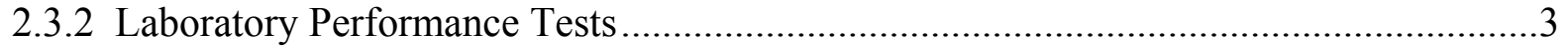

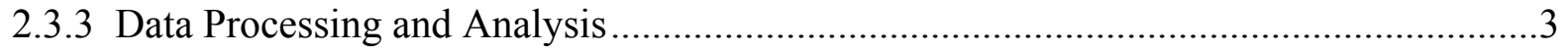

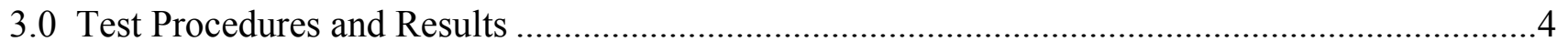

3.1 Description of Components......................................................................................... 4

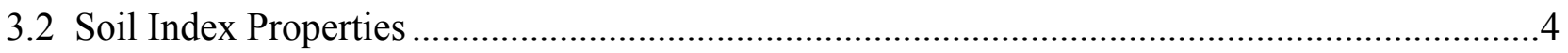

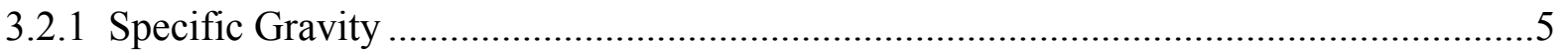

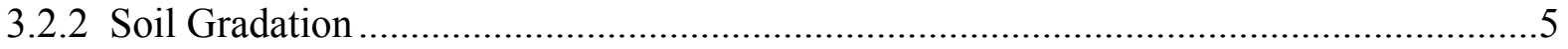

3.2.3 Optimum Moisture Content and Maximum Dry Density ..........................................6

3.2.4 Liquid Limit, Plastic Limit, and Plasticity Index ................................................

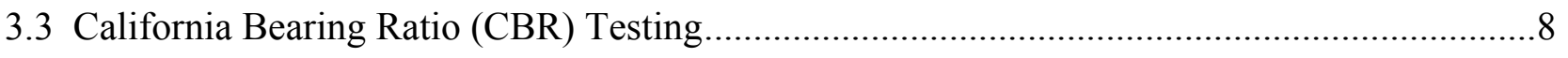

3.3.1 Results from the Native Soil Samples ................................................................. 9

3.3.2 Results from Geofiber-Reinforced Soil Samples.................................................10

3.3.3 Results from Soil Samples Improved with Synthetic Fluid.....................................12

3.3.4 Results from Samples Improved by Geofibers and Synthetic Fluid...........................14

3.3.5 Results from Samples Compacted with Non-Standard Compactive Effort..................16

3.4 Unconsolidated-Undrained (UU) Triaxial Compression Tests ...........................................19

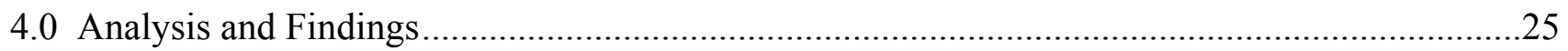

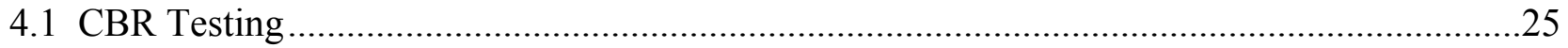

4.2 Effect of Compactive Effort on Soil Improvement …....................................................29

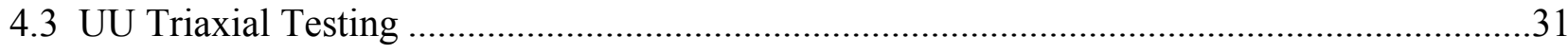

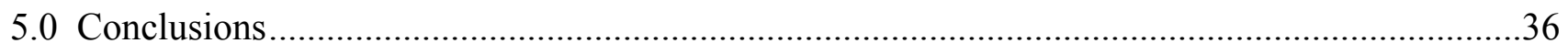

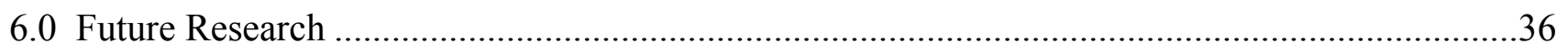

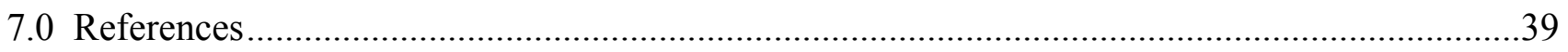

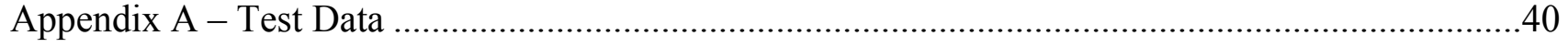

Appendix B - FiberSoils GEOFIBER ${ }^{\circledR}$ 3627BT Product Data .....................................................43 
Appendix C - Earth Armour Limited Product Data ....... 
Table of Figures

Figure 1: Sample mixture of soil, water, and geofibers. …................................................. 4

Figure 2: Particle Size Distribution curve for Bethel silty sand ............................................... 6

Figure 3: Optimum moisture content curve for the Bethel silty sand. ....................................... 7

Figure 4: CBR values at each 0.100 inch depth of penetration for each moisture content. .............. 9

Figure 5: Investigation of the Optimum Fiber Content (OFC) curve for the Bethel silty sand and

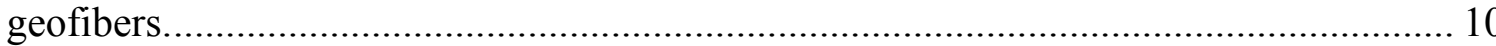

Figure 6: Investigation of the Optimum Fiber Content (OFC) curve for the Bethel silty sand and geofibers using CBR values.

Figure 7: Investigation of the Optimum Synthetic Fluid Content (OSFC) curve for the Bethel silty sand and Earth Armour - Arctic.

Figure 8: Investigation of the Optimum Synthetic Fluid Content (OSFC) curve for the Bethel silty sand and Earth Armour - Arctic using CBR values.

Figure 9: Comparison of CBR values between samples with synthetic fluid, water, and geofibers.15

Figure 10: CBR values at each 0.100 inch depth of penetration for each moisture content. ............ 16

Figure 11: CBR values at each fiber content for each 0.100 inch depth of penetration at OMC...... 17

Figure 12: CBR values at each 0.100 inch depth of penetration for each fiber content at OMC...... 17

Figure 13: CBR values at each 0.100 inch depth of penetration for each change in synthetic fluid content while holding the moisture content constant at six percent.

Figure 14: CBR values at each 0.100 inch depth of penetration for each change in synthetic fluid content while holding the moisture content and fiber content constant at six percent and 0.5 percent, respectively.

Figure 15: Deviatoric stress-axial strain response and Mohr failure envelope from soil samples prepared at a mixture of $0 / 11 / 0$ and subjected to UU Triaxial test.....................20

Figure 16: Deviatoric stress-axial strain response and Mohr failure envelope from soil samples prepared at a mixture of $0 / 11 / 0.5$ and subjected to UU Triaxial test.

Figure 17: Deviatoric stress-axial strain response and Mohr failure envelope from soil samples prepared at a mixture of 5/6/0.5 and subjected to UU Triaxial test..... 22

Figure 18: Deviatoric stress-axial strain response and Mohr failure envelope from soil samples prepared at a mixture of $3 / 6 / 0.5$ and subjected to UU Triaxial test.

Figure 19: Deviatoric stress-axial strain response and Mohr failure envelope from soil samples prepared at the mixture of $7 / 6 / 0.5$ and subjected to UU Triaxial test. 24

Figure 20: Comparison of CBR values between native soil samples with and without OFC 25

Figure 21: Comparison of CBR values between samples with a total liquid content of nine percent 
Figure 22: Comparison of CBR values between samples with a total liquid content of eleven

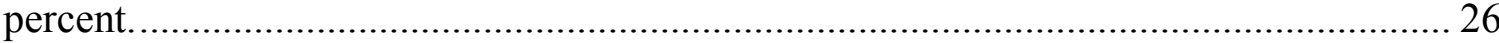

Figure 23: Comparison of CBR values between samples with a total liquid content of thirteen

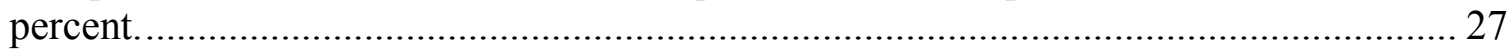

Figure 24: Comparison of CBR values between samples with synthetic fluid, water, and geofibers.28

Figure 25: Comparison of CBR values between aged samples with fiber and the same total liquid

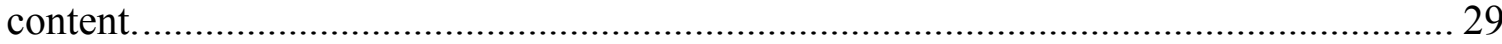

Figure 26: Comparison of CBR values between samples prepared with non-standard compactive effort and those prepared with Modified Proctor

Figure 27: Comparison of stress-strain response of various soil samples subjected to UU triaxial testing at different confining pressures.

Figure 28: Failure mechanisms of umimproved and improved soil samples 


\subsection{Acknowledgements}

The research reported herein was performed by the Institute of Northern Engineering, University of Alaska Fairbanks (UAF), and was made possible through funding by the Alaska University Transportation Center and also through funding by Peak Civil Technologies, a division of Peak Oilfield Service Company, Anchorage, Alaska. 


\subsection{Background}

\subsection{Problem Statement}

Alaska University Transportation Center (AUTC) was approached by Peak Civil Technologies (PCT) for a collaborative research effort on a newly introduced soil stabilization technique that shows promise for transportation infrastructure projects in the North. Originally developed under PCT's leadership, this technique uses a combination of two non-traditional stabilizer agents: geofibers and synthetic fluids. PCT recently applied the technique in Cape Simpson, Alaska in a poorly graded sand (USCS class: SP) area and proposes to use it with silty sand (USCS class: SM) in Bethel, Alaska. This research project was an effort to answer the question, "how effective will the use of geofiber and synthetic fluid be in improving the Bethel silty sand (SM)?"

\subsection{Study Objectives}

- To evaluate the improvement of Bethel silty sand with additions of two stabilizers (geofibers and synthetic fluid) through CBR tests,

- To investigate the performance and strength of the soil at different moisture contents through undrained-unconsolidated (UU) triaxial compression tests.

\subsection{Research Plan}

To meet the study objectives, a plan outlining a research approach, anticipated research results, implementation plan, and applicability of results to practice was proposed.

A newly introduced soil stabilization approach that uses non-traditional stabilizers to improve marginal soils was evaluated using a series of laboratory tests. This research was a joint effort between AUTC and PCT. The AUTC research team coordinated with PCT to gather related information and data from recently conducted projects. The University of Alaska Fairbanks supplied a geotechnical laboratory, pavement testing facilities, and materials preparation and testing laboratories to conduct this study. A faculty member (Hazirbaba, Principal Investigator), a graduate student (Zhang), and an undergraduate student (Davis) formed the research team in this study.

\subsubsection{Literature Survey}

The most commonly used materials for stabilizing soils or marginal aggregates are asphalt, cement, lime, and fly ash. These stabilizing agents are known as "traditional stabilizers", and the literature is full of examples and well-documented case studies about their use. However, as technology and understanding of soil stabilization mechanisms improve, additional methods and products - often known as "non-traditional stabilizers" - have been developed. Electrolytes, enzymes, mineral pitches, clay fillers and acrylic polymers are some examples of non-traditional stabilizers (Scholen, 1992). Our initial and limited literature search for non-traditional soil stabilizers indicated no documentation of the use of synthetic fluid as a stabilizer. There have been some applications of synthetic fluid for dust control but not specifically for soil improvement. To the best of our knowledge, the only soil improvement application is the Cape Simpson Project PCT performed (Brangan et al., 2007). 


\subsubsection{Laboratory Performance Tests}

Soil improvement was evaluated in terms of CBR (California Bearing Ratio) values and triaxial compressive strength, in accordance with ASTM or AASHTO testing protocols.

The soil index properties were evaluated through the following tests:

- specific gravity (ASTM D854-06)

- soil gradation (ASTM C136-06)

- optimum moisture content and maximum dry density

(ASTM D1557-02)

- liquid limit, plastic limit, and plasticity index on the soil fines (ASTM D4318-00)

The CBR tests were performed in accordance with ASTM D1883-05, with compactive effort in accordance with ASTM D1557-02. Additional CBR tests were conducted with a non-standard compactive effort to observe compaction-dependent changes in improvement. Unconsolidated-Undrained (UU) Triaxial Compression tests were performed in accordance with AASHTO T296-05. Tests were conducted on the following:

- native soil samples;

- samples of soils reinforced with geofibers only;

- samples of soils stabilized with the synthetic fluid only;

- samples of soils stabilized with a combination of geofibers and synthetic fluid; and

- the above four sets of samples with non-standard compactive effort.

\subsubsection{Data Processing and Analysis}

Researchers analyzed laboratory test data, compared CBR values obtained from native soil samples and improved soil samples, and evaluated the stress-strain response and the compressive strength from UU Triaxial testing. 


\subsection{Test Procedures and Results}

\subsection{Description of Components}

The components used in this research were silty sand from Bethel, Alaska (USCS class: SM); FiberSoils GEOFIBERS ${ }^{\circledR} 3627 B T$ (see Appendix B); and Earth Armour Limited Earth Armour Arctic, a severely hydrotreated paraffinic synthetic fluid (see Appendix C).

An example test mixture, shown in Figure 1, contained a fiber content of five-eighths of one percent $(.625 \%)$ of the dry soil unit weight and a water content of $11 \%$ of the dry soil unit weight.

\subsection{Soil Index Properties}

PCT originally supplied the soil sample in three separate containers. The soil from each container was transferred to pans and placed in an oven $\left(105^{\circ} \mathrm{C}\right)$ to dry to constant mass. Afterward, the soil from each pan was mixed with the others to make a single, unified sample, which was then split and stored in three sealed containers. Sieve analysis was performed on samples taken from two of the three soil storage containers; test results served as a quality control check to verify consistency between storage containers after mixing and splitting the dry soil.

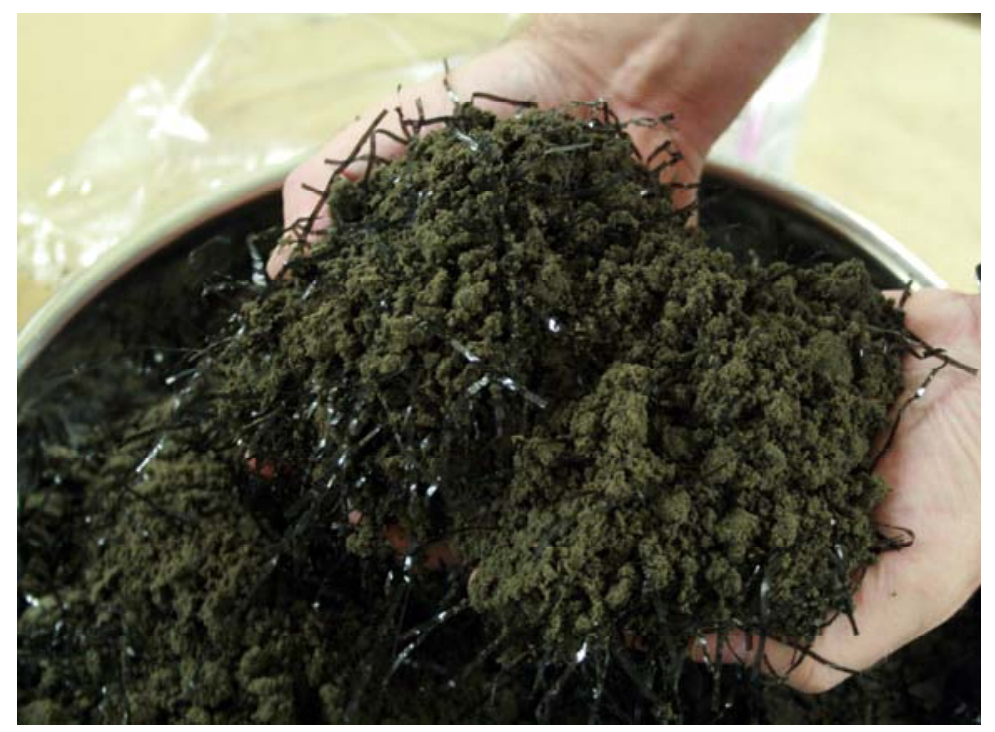

Figure 1: Sample mixture of soil, water, and geofibers. 


\subsubsection{Specific Gravity}

The specific gravity of the Bethel silty sand was found according to ASTM D864-06. The specific gravity test was performed by placing $50 \mathrm{~g}$ of soil in the pycnometer with distilled water. Entrapped air was removed from the soil-water mix by applying vacuum. Then, measurements to satisfy the following equation were performed:

$$
G_{T x}=W_{o} /\left[W_{o}+W_{a}-W_{b}\right]
$$

where

$$
\begin{aligned}
& W_{o}=\text { wight of sample of oven-dry soil, } \mathrm{g} \\
& W_{a}=\text { wight of pycnometer filled with water at temperature } T x, \mathrm{~g} \\
& W_{b}=\text { wight of pycnometer filled with water and soil at temperature } T x, \mathrm{~g} \\
& T_{x}=\text { Temperatrue of the contents of the pycnometer when } W_{b} \text { was determined, }{ }^{\circ} \mathrm{C} .
\end{aligned}
$$

The specific gravity of the Bethel silty sand sample was found to be 2.59 at the temperature of $20^{\circ} \mathrm{C}$.

\subsubsection{Soil Gradation}

Sieve analysis testing was performed in accordance with ASTM C136-06 using U.S. Standard eight-inch diameter sieves. The sieve stack contained the following sizes, stacked in order of decreasing opening size: \#4, \#16, \#30, \#50,\#100,\#140,\#200, and a pan.

Weights were obtained using a Mettler PC1616 digital scale, balanced and verified with calibration weights to read within 0.1 gram. Each test sample was split and measured to approximately, but no less than, one kilogram.

The sieve stack and soil samples were placed in a Tyler Ro-Tap 8" RX-29 (Model B) shaker, and then shaken for fifteen minutes.

After shaking, the contents on each sieve were weighed in cumulative fashion and the percent passing each sieve was calculated.

The particle distribution curves from the sieve analysis tests are shown in Figure 2, and recorded test data is included in Appendix A. The two samples gave nearly identical curves, indicating that the unified sample was consistent in gradation between storage containers. Consistency of the third container was assumed to be similar to that of the first two. 




Figure 2: Particle size distribution curve for Bethel silty sand.

\subsubsection{Optimum Moisture Content and Maximum Dry Density}

The optimum moisture content and dry density of the Bethel silty sand were found in accordance with ASTM D1557-02.

Weight measurements were obtained using a Mettler PC1616 digital scale and a Sartorius $60,000 \mathrm{~g}$ digital scale. Dry soil samples were weighed to approximately $2 \mathrm{~kg}$. Water was measured to $0.1 \mathrm{~g}$ of the target moisture content for each test. Target moisture contents of up to $20 \%$ of the dry soil weight were tested in $2 \%$ increments.

The soil and water test samples were hand-mixed and stored in sealed containers for a minimum of one hour before compaction.

Compaction was performed by a SoilTest Mechanical Soil Compactor (model CN-4235) in four-inch diameter molds conforming to the requirements of ASTM D1557-02. Each test was performed in five lifts and twenty-five blows per lift using a round foot on the mechanical rammer.

After compaction, the test samples were dried, either in whole or in part, to determine the resulting moisture content. Data points separated by greater than $2 \%$ moisture content near 
the apparent optimum moisture point were supplemented by additional tests; researchers used moisture contents estimated to split the difference.

Figure 3 shows the Optimum Moisture Content (OMC) was found to be near 11\%, which corresponds to a dry density of $110.8 \mathrm{lb} / \mathrm{ft}^{3}$.

\subsubsection{Liquid Limit, Plastic Limit, and Plasticity Index}

To find the liquid and plastic limits of the Bethel silty sand, researchers followed procedures outlined in ASTM D4318-84. The number of blows required to close the groove, as per the standard, was always less than 25; thus the liquid limit could not be determined. The Bethel silty sand was also found to be non-plastic.

\section{Optimum Moisture Content}

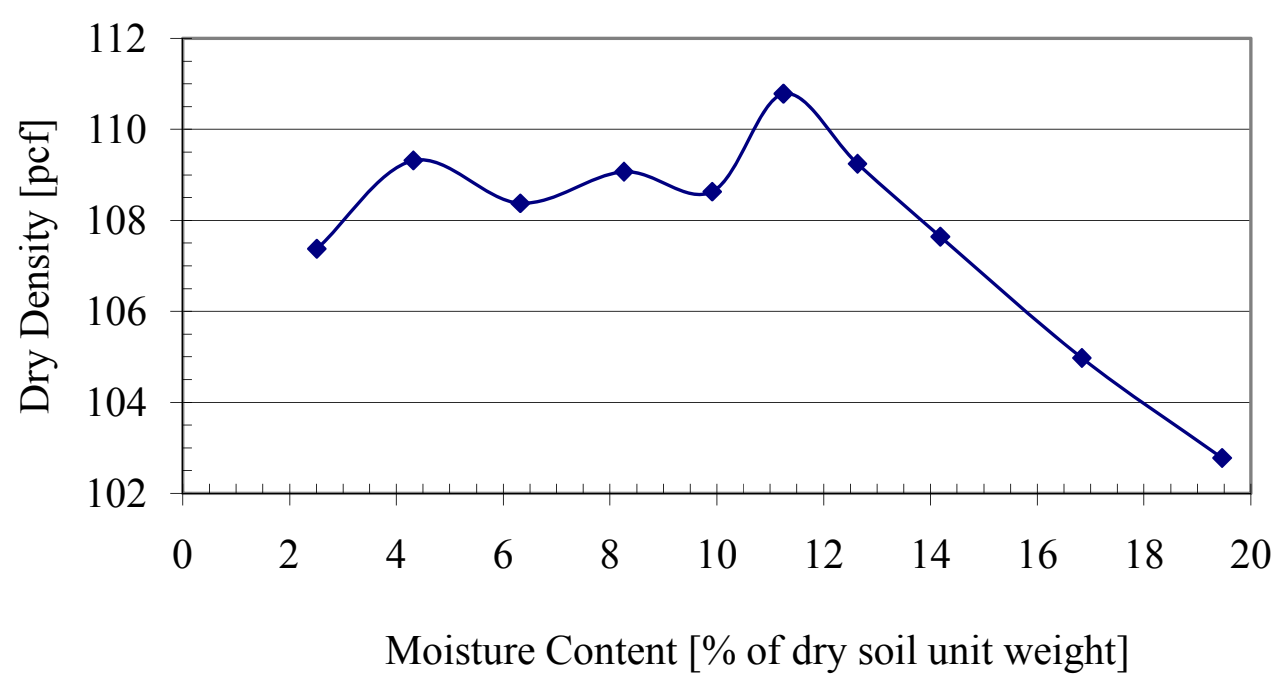

Figure 3: Optimum moisture content curve for Bethel silty sand. 


\subsection{California Bearing Ratio (CBR) Testing}

CBR testing was conducted in accordance with ASTM D1883-05. Compaction was performed in accordance with ASTM D1557-02, in molds meeting the requirements of ASTM D1883-05, including spacer. For the non-standard compactive effort, compaction was performed in accordance with ASTM D698-00a, except that a drop height of eighteen inches was used instead of twelve inches, and the six-inch molds used conformed to the requirements of ASTM D69800a. Compaction was performed by a SoilTest Mechanical Soil Compactor (model CN-4235). A sectional foot was used on the mechanical rammer for compaction of all CBR test samples.

The CBR test apparatus was a SoilTest G-900 VersaLoader, having a maximum capacity of 10,000 pounds. Prior to testing, the proof-ring load was correlated with a recently calibrated $22,000 \mathrm{lb}$ load cell and digital readout.

Testing was conducted at a speed of approximately $0.050 \mathrm{in} / \mathrm{min}$. Test readings were taken, as a minimum, at the following displacements: 0.025 in., 0.050 in., 0.075 in., 0.100 in., 0.125 in., 0.150 in., 0.175 in., 0.200 in., 0.300 in., 0.400 in., and 0.500 in. For some tests, readings were taken at each 0.025 inch displacement through the entire test range of zero to .5 inches.

The soil samples were not soaked, and a surcharge of $10 \mathrm{lbs}$ was used.

A nomenclature was adopted for identifying samples: "SFC/MC/F", where SFC was the synthetic fluid content as a percentage of dry soil weight, $\mathrm{MC}$ was the moisture content as a percentage of dry soil weight, and $\mathrm{F}$ was the geofiber content as a percentage of dry soil weight. For example, a sample identified as " $3 / 6 / 0.5$ " had an estimated synthetic fluid content of $3 \%$ of dry soil weight, an estimated moisture (water) content of $6 \%$ of dry soil weight, and an estimated fiber content of .5\% of dry soil weight. Similarly, samples identified as " $0 / 11 / 0$ " contained a moisture (water) content target of $11 \%$ of dry soil weight and no synthetic fluid or fiber; the actual amount of moisture content in the sample was measured and recorded after oven drying.

Test samples with liquid contents of synthetic fluid and water mixtures are reported as estimated quantities of each of these components; similarly, the dry density is an estimate for these samples. Samples that contained water as the only liquid were oven-dried $\left(105^{\circ} \mathrm{C}\right)$ to determine moisture content and the calculated dry density was reported. Oven-drying was not an adequate procedure for samples with liquid contents of synthetic fluid and water mixtures. No readily available means of identifying the ratio loss of water to synthetic fluid during oven-drying was found, and thus estimates are used instead of quantifiable amounts. The following assumptions were made regarding synthetic fluid and water mixtures: total liquid loss is negligible; and synthetic fluid and water are evenly distributed within the test sample. 


\subsubsection{Results from the Native Soil Samples}

CBR tests were conducted on mixtures of soil and water at the optimum moisture content (OMC), a target value of $11 \%$, " $0 / 11 / 0$ "; at OMC plus $2 \%$, a target value of $13 \%$, " $0 / 13 / 0$ "; and at OMC minus $2 \%$, a target value of nine percent, " $0 / 9 / 0 "$.

Dry soil samples were weighed to $4.5 \mathrm{~kg}$, and water was measured to within $0.1 \mathrm{~g}$ of the target amount. The soil and water samples were hand-mixed and stored in sealed containers for at least one hour before testing. Care was taken to ensure minimal moisture loss during testing.

Samples were mixed, compacted, tested for bearing capacity, and then removed from the test mold, loosened by hand, and re-mixed with remaining material. Each CBR test consisted of a series of three compactions and bearing tests on the same soil mixture; reported CBR values are the average of these three tests. The entire mold of the third test of the series was oven-dried to determine moisture content. The exception to this procedure was the test sample with a target of $13 \%$ moisture; this test was conducted on three separate samples due to loss of up to $.5 \%$ of water, which bled out during compaction and bearing testing. Moisture contents in the other series of compaction and bearing tests showed minimal loss (i.e., less than $0.2 \%$ of the target).

Figure 4 presents test results for the native soil samples. Recorded test data appears in Appendix A. Results show that soil at the optimum moisture content displays the highest bearing capacity at each 0.100 inch of penetration, relative to soils with other moisture contents. The CBR value at $\mathrm{OMC}$ was found to be 31.5 at 0.200 inch of penetration.

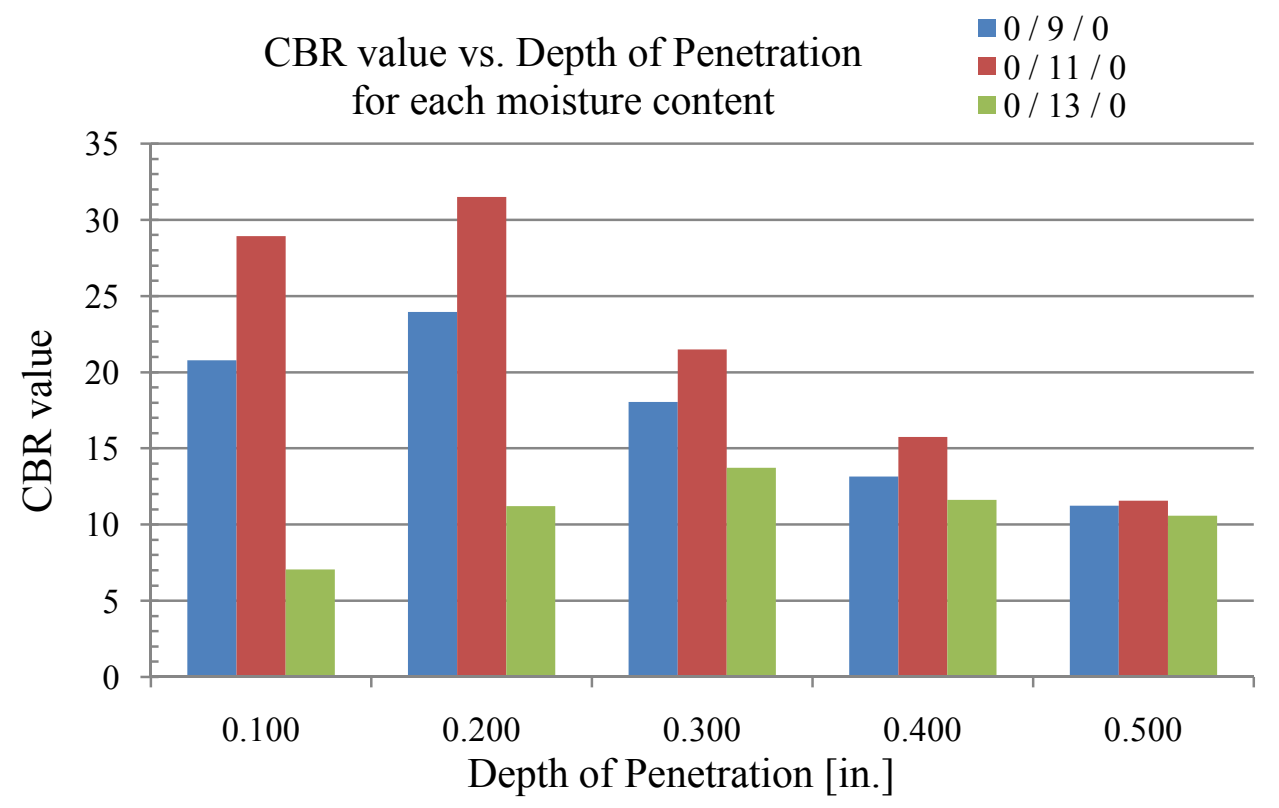

Figure 4: CBR values at each 0.100 inch depth of penetration for each moisture content. 


\subsubsection{Results from Geofiber-Reinforced Soil Samples}

Following OMC tests on native soil samples with varying moisture contents, an effort was made to determine the optimum fiber content (OFC). Initially, a process similar to the optimum moisture content standard, ASTM D1557-02, was used to find the OFC: The moisture content was held constant at the OMC and varying amounts of geofibers were added to different test samples. Tests in standard four-inch molds produced a percent fiber versus dry density curve that gave inconclusive results. As shown in Figure 5, a plateau in dry density is apparent between the values of 0.3 percent and one percent (i.e., dry density values do not change more than $\left.1 \mathrm{lb} / \mathrm{ft}^{3}\right)$, and then sharply decline as fiber content increases greater than one percent of the dry soil weight.

The values shown in Figure 5, in conjunction with the observed fiber length (i.e., 2.75 inches), led to the conclusion that four-inch molds do not appear to have sufficient space for the fibers to adequately disperse to their full length in the compact soil. In their product literature, FiberSoils suggests that "dosage rates are typically determined to be 0.1 to 0.3 percent of the soil's dry unit weight", although they do not state to which soil types this recommendation applies (Brangan, 2007). From the Peak Civil Technologies (PCT) presentation on their Cape Simpson project, their field application was noted as "polypropylene soil fibers at 0.15 pounds per square foot blended uniformly to 6 inch depth and compacted." The Cape Simpson, Alaska material (USCS class: SP) was reported to have a dry density of $108.98 \mathrm{lb} / \mathrm{ft}^{3}$ using ASTM D698 for compactive effort. (Brangan, 2007) An estimate for the amount of geofibers used at Cape Simpson was calculated to be approximately $0.45 \%$ of dry soil unit weight.

\section{Optimum Fiber Content}

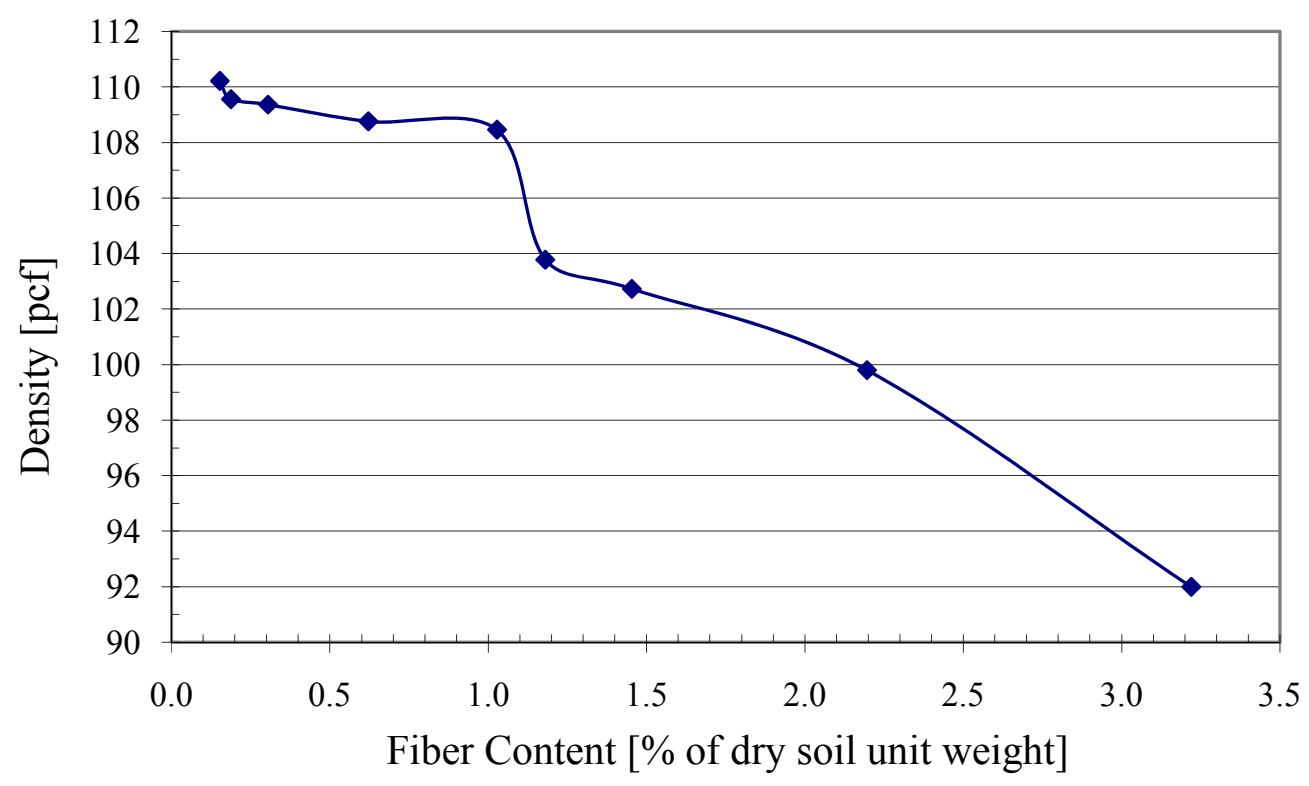

Figure 5: Investigation into the optimum fiber content (OFC) curve for Bethel silty sand and geofiber. 
CBR tests were conducted on mixtures of soil, water, and geofiber at the OMC, a target value of $11 \%$. Investigation of optimum fiber content started at 0.5 percent of dry soil weight, and was varied by $0.125 \%$ above and below (i.e., tests " $0 / 11 / 0.375$ ", " $0 / 11 / 0.5$ ", and " $0 / 11 / 0.625$ ").

As with the tests on native soil samples, each sample of dry soil was measured to $4.5 \mathrm{~kg}$, and moisture content was measured to within $0.1 \mathrm{~g}$ of the target amount. The soil was hand-mixed and stored in sealed containers at least one hour before mixing with the fibers. Fiber content was measured to within $0.1 \mathrm{~g}$ of the target amount. Fibers were mixed into the soil by adding alternating layers of soil and fiber to a stainless-steel mixing bowl. The bowl contents were then mixed by hand, using a manipulation technique that simulated rotor-tilling action, until the fibers were evenly distributed in the soil.

Samples were mixed, compacted, tested for bearing capacity, and then removed from the test mold, loosened by hand, and re-mixed with remaining material. Each CBR test consisted of a series of three compactions and bearing tests on the same soil mixture; CBR values reported are the average of these three tests. Care was taken to ensure minimal moisture loss during testing. A portion of the third test of the series was oven-dried to determine moisture content. The remainder was compacted and set aside to age in ambient room conditions for one week prior to performing a bearing test on this aged sample.

Figure 6 presents the CBR values at various geofiber contents, ranging from 0 to $0.625 \%$. It appears that the bearing capacity is near $0.5 \%$ of dry soil weight under the given test conditions. By adding $0.5 \%$ fiber at $\mathrm{OMC}$, the $\mathrm{CBR}$ value at 0.200 inch penetration increases from 31.5 to 63.8; this indicates a $102.5 \%$ improvement in terms of CBR value. Recorded test data is included in Appendix A.

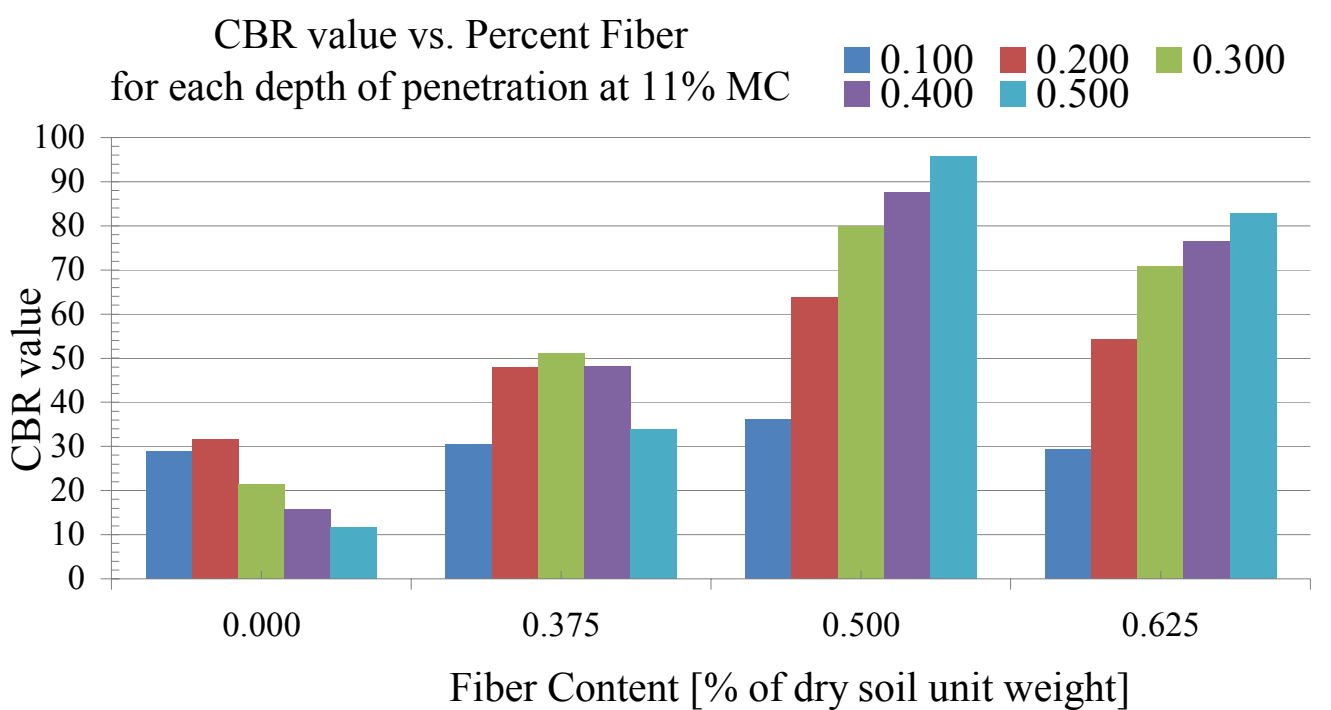

Figure 6: Investigation of the optimum fiber content (OFC) curve for Bethel silty sand and geofiber using CBR values. 


\subsubsection{Results from Soil Samples Improved with Synthetic Fluid}

According to a presentation by Todd Hawkins (Earth Armour product distributor and soil stabilization consultant), synthetic fluid is typically used at one quarter of the amount of water added (1:4). For example, 2\% synthetic fluid to $8 \%$ water (Brangan, 2007).

The soil optimum synthetic fluid content (OSFC) and estimated dry density were investigated in a procedure similar to that used to find the OMC, in accordance with ASTM D1557-02. Compaction was performed by a SoilTest Mechanical Soil Compactor (model CN-4235). Weights were obtained with a Mettler PC1616 digital scale and a Sartorius 60,000g digital scale.

Compaction for all samples was performed in five lifts and twenty-five blows per lift using a round foot on the hammer, and compaction occurred in standard four-inch molds. Dry soil samples were weighed to approximately $2 \mathrm{~kg}$ and synthetic fluid was added in small percentages of the dry soil weight. The samples were hand-mixed and stored in sealed containers for a minimum of 30 minutes before compaction. After compaction, an estimated dry density was calculated based on two assumptions, that none of the synthetic fluid was lost during compaction and that the synthetic fluid was evenly dispersed in the soil.

It was observed that while mixing the synthetic fluid with the dry soil, the fluid appeared disposed to form clumps and did not readily disperse through the soil as water would, especially when mixing small amounts of fluid. Substantial effort was made to ensure even dispersal of fluid in the soil; clumps were broken up by hand, and mixing continued until the soil mixture appeared consistent throughout.

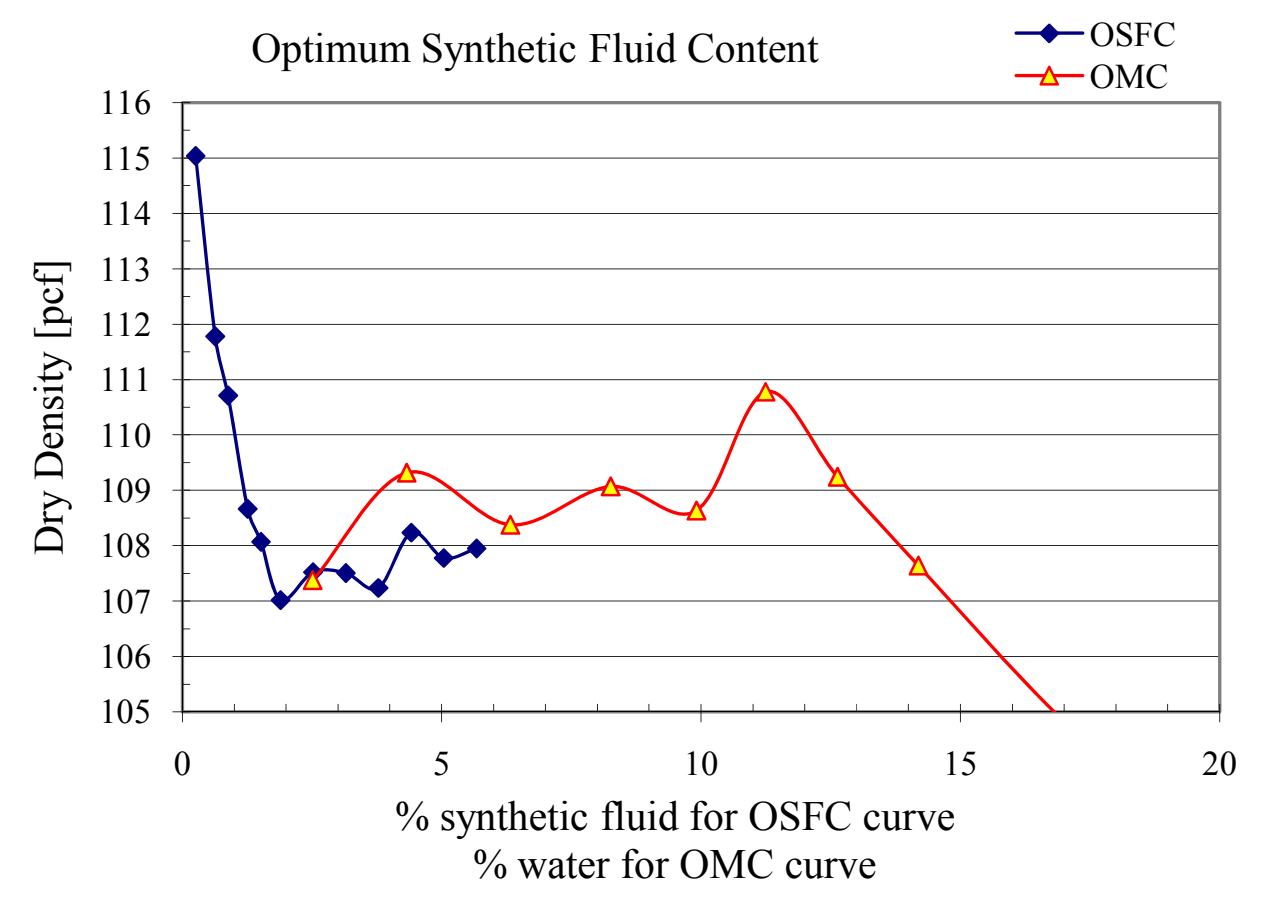

Figure 7: Investigation of the optimum synthetic fluid content (OSFC) curve for Bethel silty sand and Earth Armour - Arctic synthetic fluid. 
Results for finding the OSFC using the method described above were inconclusive. Figure 7 shows a curve of percent synthetic fluid versus dry density plotted and overlain with the percent moisture versus dry density curve. The two curves appear similar to each other, and further investigation using dry soil and synthetic fluid without any water content was abandoned in favor of a different technique.

A quick, but significant, test was performed to explore the effect of using a mixture of synthetic fluid and water, but substantially altering the ratio of fluid-to-water while keeping the total liquid content the same. The total liquid content was held at the OMC point ( $11 \%$ of dry soil weight) and two mixes were chosen: 3/8/0 and 7/4/0. Despite the difference in ratio of fluid-to-water, the estimated dry densities of the two compaction tests resulted in a difference of less than $0.1 \mathrm{lb} / \mathrm{ft}^{3}$.

In a discussion with Todd Hawkins concerning the synthetic fluid's properties when mixed with silty sand, Hawkins indicated that he had no experience mixing the synthetic fluid with dry silty sand similar to that provided from Bethel, Alaska. He recommended that some moisture be added to the soil prior to adding the fluid, as this would simulate field conditions where in-situ moisture would be present, as well as potentially aiding fluid dispersal in the soil. (Hawkins, 16 July 2007) A follow up discussion with Billy Connor, AUTC Director, gave insight to a starting point for this new procedure; Mr. Connor indicated that, although the in-situ moisture content of a soil would change through each season, the rule-of-thumb he recommended was to assume the in-situ moisture content was between 60 and 70\% of optimum. (Connor, 16 July 2007) At this point, researchers decided to investigate the soil's bearing capacity while holding the moisture constant at $6 \%$ and varying the synthetic fluid content above and below the total liquid content of 11\%. Three mixtures were selected for testing: 3/6/0,5/6/0, and 7/6/0. Mixture 5/6/0 was chosen to match the total liquid content of $11 \%$; the other two mixtures represent varying the fluid content by $2 \%$ on either side of the $11 \%$ total liquid content.

Dry soil samples were weighed to $4.5 \mathrm{~kg}$, and water was measured to within $0.1 \mathrm{~g}$ of the target moisture content amount. The samples were hand-mixed and stored in sealed containers for at least one hour before mixing with the synthetic fluid. The synthetic fluid was measured to within $0.1 \mathrm{~g}$ of the target synthetic fluid content amount. The samples were hand-mixed and stored in sealed containers for at least 30 minutes before testing. Care was taken to ensure minimal moisture loss during mixing and testing.

Samples were mixed, compacted, tested for bearing capacity, and then removed from the test mold, loosened by hand, and re-mixed with remaining material. Each CBR test consisted of a series of three compactions and bearing tests on the same soil mixture; CBR values reported are the average of these three tests. After compaction, estimated dry densities were calculated.

CBR test results from samples containing synthetic fluid and water mixtures are shown in Figure 8. Recorded test data is included in Appendix A. These test results do not provide an immediately apparent conclusion. 


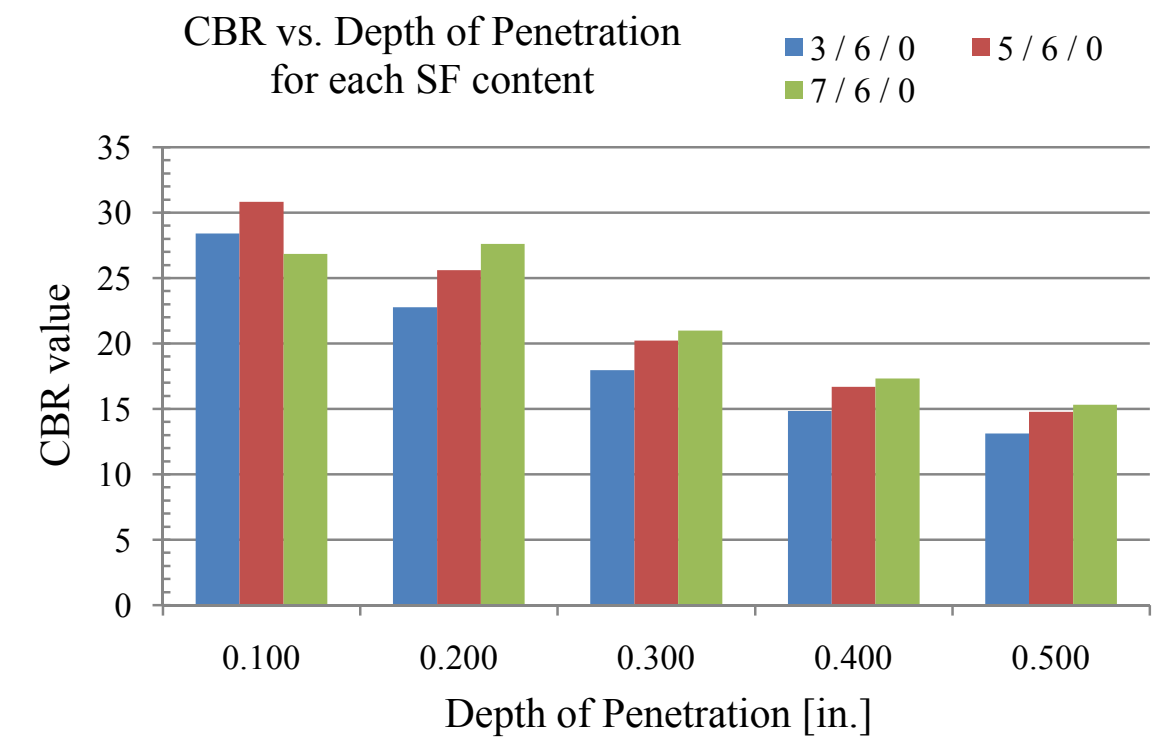

Figure 8: Investigation of the optimum synthetic fluid content (OSFC) curve for Bethel silty sand and Earth Armour - Arctic synthetic fluid using CBR values.

\subsubsection{Results from Samples Improved by Geofibers and Synthetic Fluid}

To observe the effects of combined synthetic fluid with geofibers on the bearing capacity of the Bethel silty sand, the following series of samples were prepared for CBR testing: $3 / 6 / 0.5$, $5 / 6 / 0.5$, and $7 / 6 / 0.5$. As indicated in the nomenclature, the moisture content and fiber content were held constant and the amount of synthetic fluid was varied on either side of the optimum liquid content of $11 \%( \pm 2 \%)$. One-half of one percent of the dry soil weight was selected as the optimum fiber content (OFC) as noted above.

Dry soil samples were weighed to $4.5 \mathrm{~kg}$, and water was measured to within $0.1 \mathrm{~g}$ of the target moisture content amount. The samples were hand-mixed and stored in sealed containers for at least one hour before mixing with the synthetic fluid. The synthetic fluid was measured to within $0.1 \mathrm{~g}$ of the target synthetic fluid content amount. The samples were hand-mixed and stored in sealed containers for at least 30 minutes before testing. Care was taken to ensure minimal moisture loss during mixing and testing.

Fibers were mixed into the soil by adding alternating layers of soil and fiber to a stainless-steel mixing bowl. The bowl contents were then mixed by hand, using a manipulation technique that simulated rotor-tilling action, until the fibers were evenly distributed in the soil. 
Samples were mixed, compacted, tested for bearing capacity, and then removed from the test mold, loosened by hand, and re-mixed with remaining material. Each CBR test consisted of a series of three compactions and bearing tests on the same soil mixture; reported CBR values are the average of these three tests. After the third bearing test was performed, the remaining material was compacted and set aside to age in ambient room conditions for one week prior to performing a bearing test on these aged samples. After compaction, an estimated dry density was calculated.

CBR test results from samples containing synthetic fluid and water mixtures are shown in Figure 9. Recorded test data is included in Appendix A. These test results do not provide an immediate conclusion, although the CBR values from the sample with five percent synthetic fluid and six percent water appears to level out whereas the CBR values for the other mixtures continue to increase.

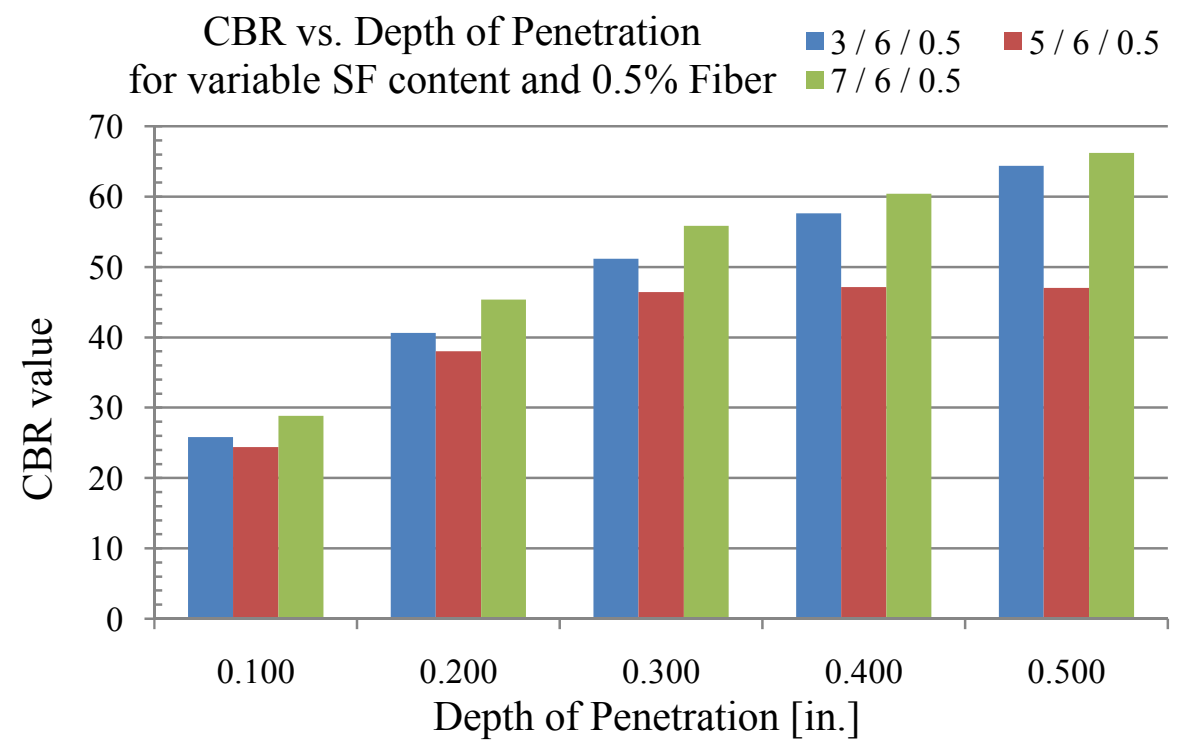

Figure 9: Comparison of CBR values between samples with synthetic fluid, water, and geofiber. 


\subsubsection{Results from Samples Compacted with Non-Standard Compactive Effort}

Additional CBR tests were conducted with a non-standard compactive effort and may be used to observe soil improvement by compaction effort. For the non-standard compactive effort, compaction was performed in accordance with ASTM D698-00a, except that a drop height of eighteen inches was used instead of twelve inches; the six-inch molds used conformed to the requirements of ASTM D698-00a. Compaction was performed by a SoilTest Mechanical Soil Compactor (model CN-4235). A sectional foot was used on the mechanical rammer for compaction of all CBR test samples. Recorded test data is included in Appendix A for all nonstandard compactive effort tests. The results of these tests are presented in Figures 10 through 14, and a discussion of the results is provided in the Analysis of Findings and Discussion section (Section 4.2).

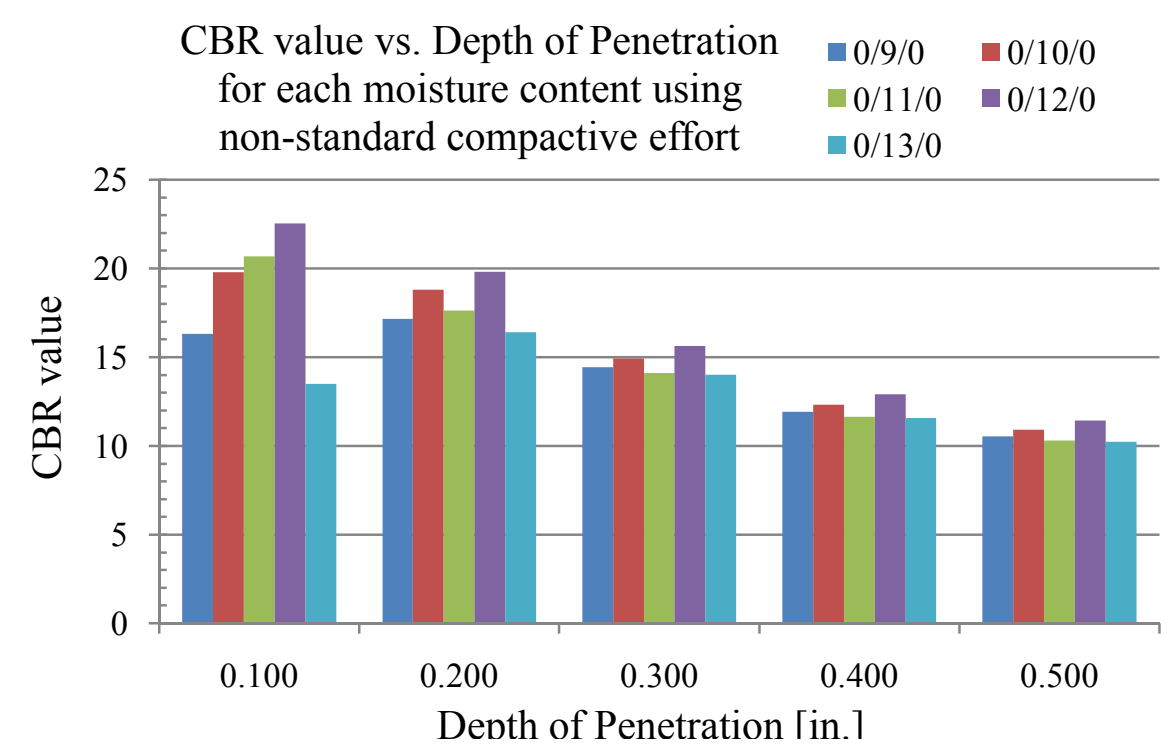

Figure 10: CBR values at each 0.100 inch depth of penetration for each moisture content. 


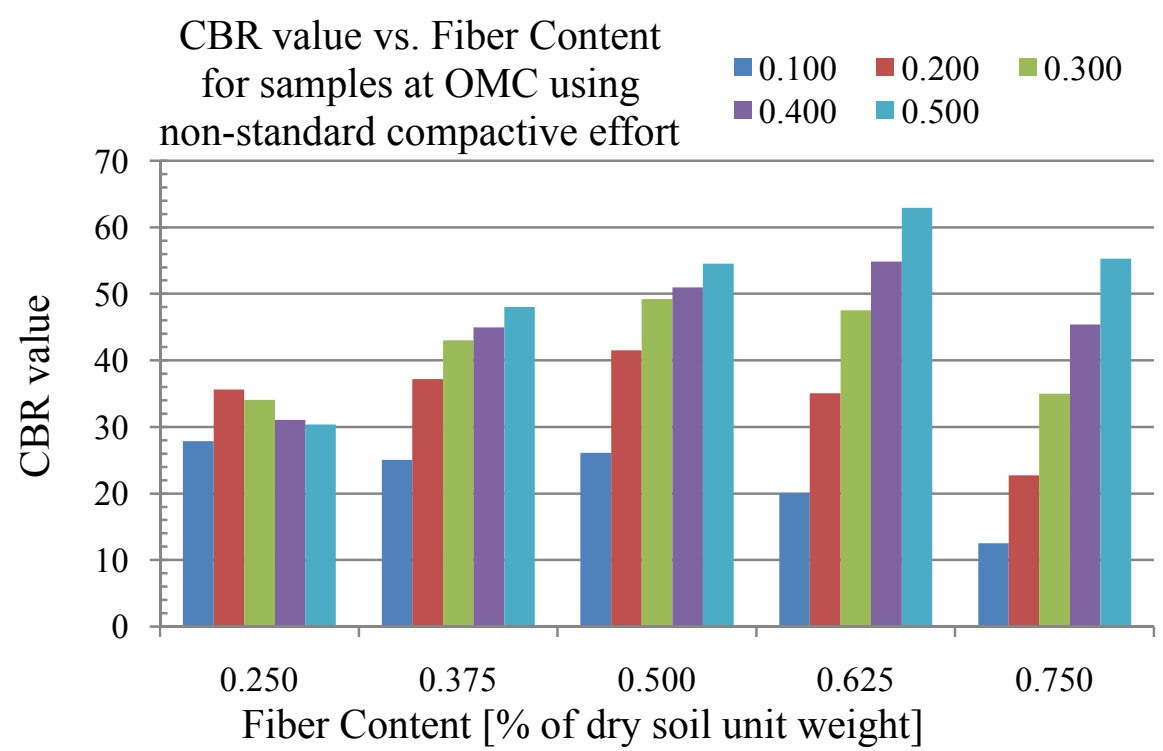

Figure 11: CBR values at each fiber content for each 0.100 inch depth of penetration at OMC.

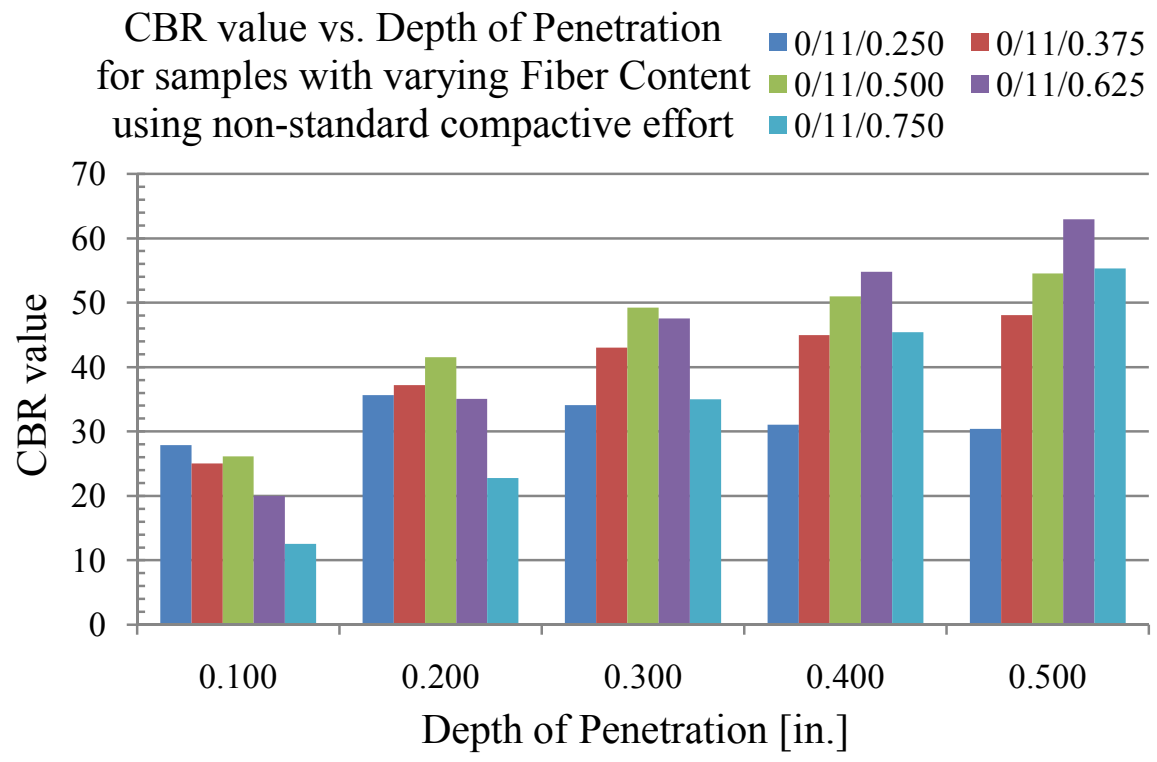

Figure 12: CBR values at each 0.100 inch depth of penetration for each fiber content at OMC. 


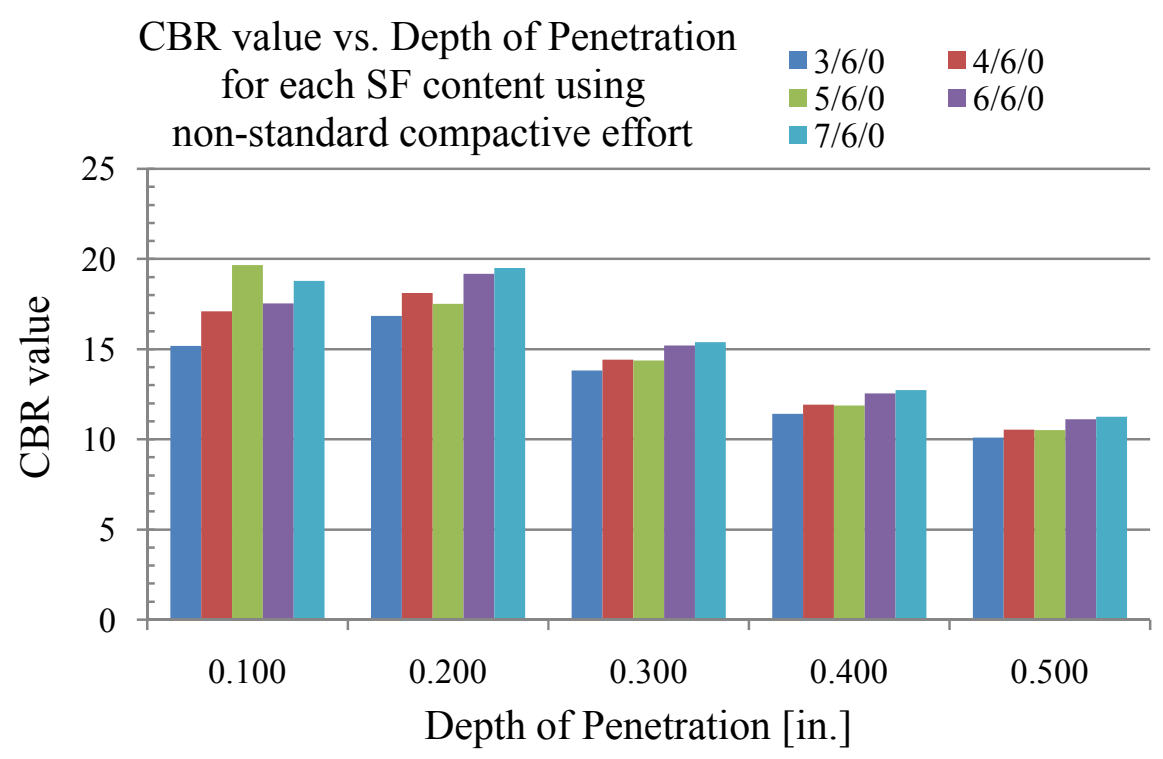

Figure 13: CBR values at each 0.100 inch depth of penetration for each change in synthetic fluid content while holding the moisture content constant at $6 \%$ (no fiber content).

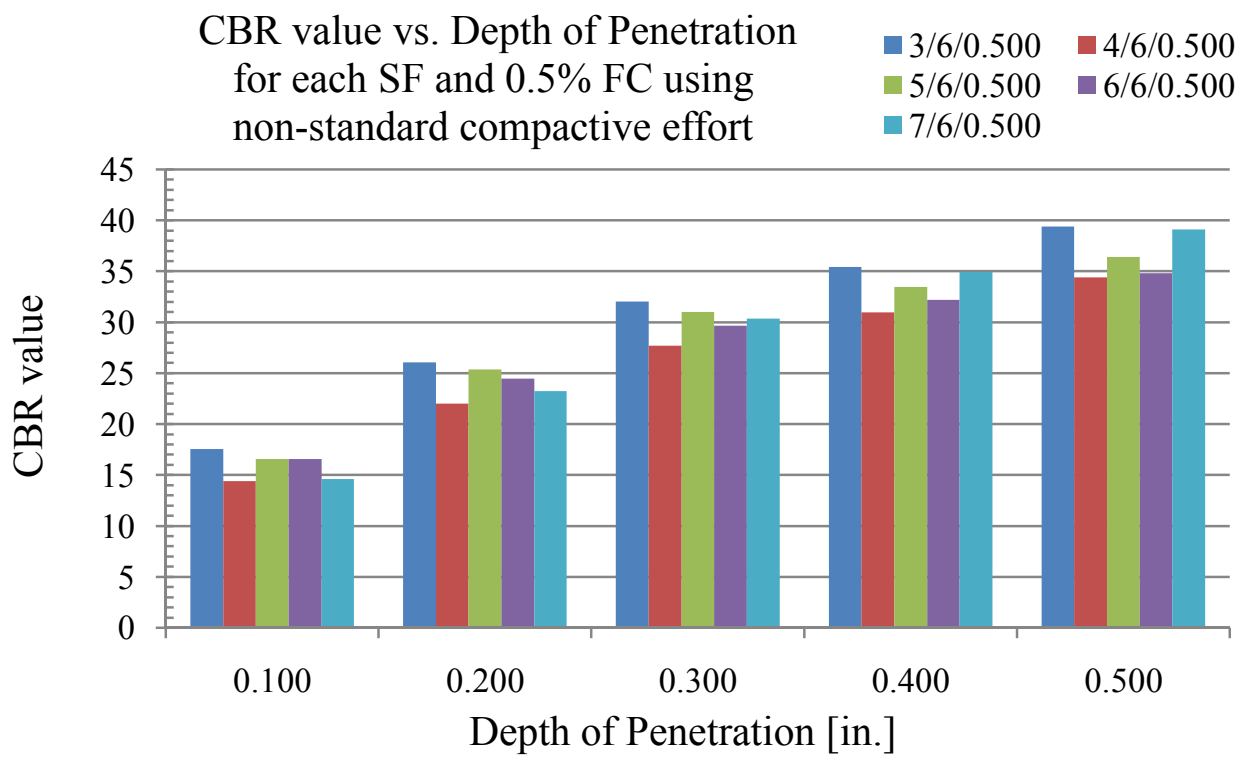

Figure 14: CBR values at each 0.100 inch depth of penetration for each change in synthetic fluid content while holding the moisture content and fiber content constant at $6 \%$ and $0.5 \%$, respectively. 


\subsection{Unconsolidated-Undrained (UU) Triaxial Compression Tests}

Unconsolidated, undrained (UU) triaxial compressive strength tests were performed on native soil samples compacted at OMC, geofiber-reinforced samples at OMC, and samples improved with a combination of geofiber and synthetic fluid. The AASHTO T 296-05 procedure was followed for all of the UU tests.

The soil samples subjected to UU tests were classified in five groups. Following the nomenclature established for CBR testing above, the results from each group are labeled as "SFC/MC/F", where SFC is the synthetic fluid content as a percentage of dry soil weight, $\mathrm{MC}$ is the moisture content as a percentage of dry soil weight, and $\mathrm{F}$ is the geofiber content as a percentage of dry soil weight. Accordingly, the soil sample groups are: (1) samples prepared at the mixture of $0 / 11 / 0$; (2) samples prepared at the mixture of $0 / 11 / 0.5$; (3) samples prepared at the mixture of $5 / 6 / 0.5$; (4) samples prepared at the mixture of $3 / 6 / 0.5 ;$; (5) samples prepared at the mixture of $7 / 6 / 0.5$.

Three soil samples were prepared for each group and each of these samples was tested at a different confining pressure. The confining pressures were $2.5 \mathrm{psi}, 5 \mathrm{psi}$ and $10 \mathrm{psi}$. The UU testing results are presented in Figures 15 through 19 in terms of deviatoric stress-axial strain response and Mohr failure envelope. Discussion of findings from the UU tests is presented in the Analysis of Findings and Discussion section (Section 4.3). 


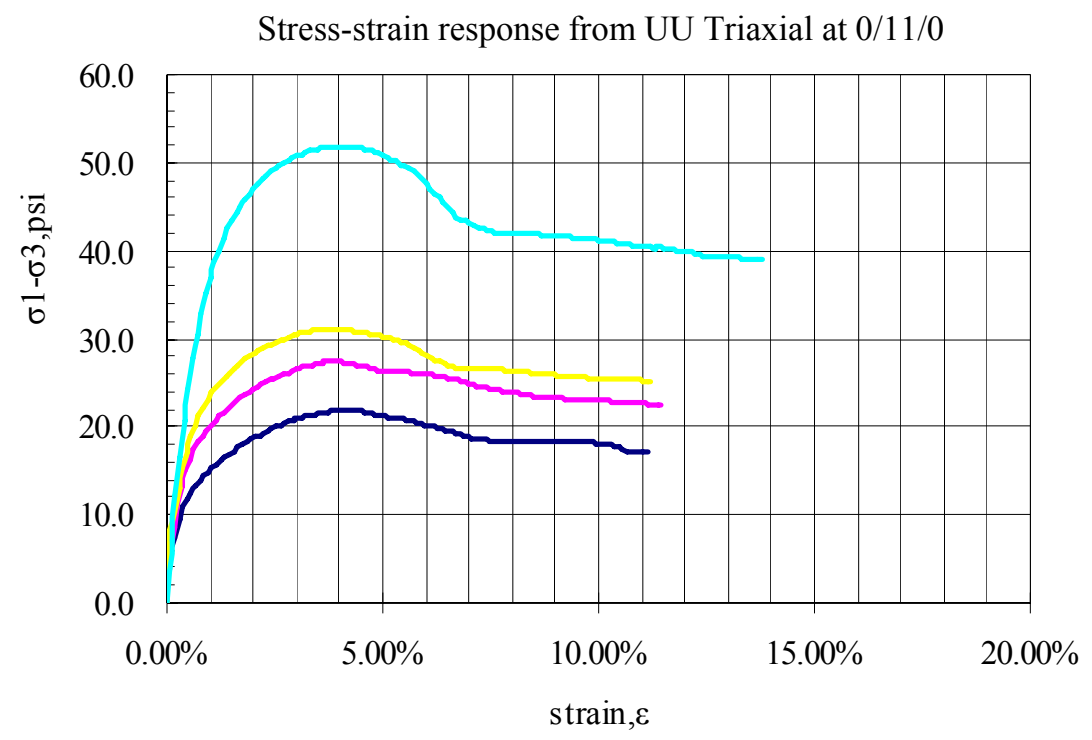

$-\sigma 3=2.5 \mathrm{psi}-\sigma 3=4.0 \mathrm{psi}-\sigma 3=5.0 \mathrm{psi}-\sigma 3=10.0 \mathrm{psi}$

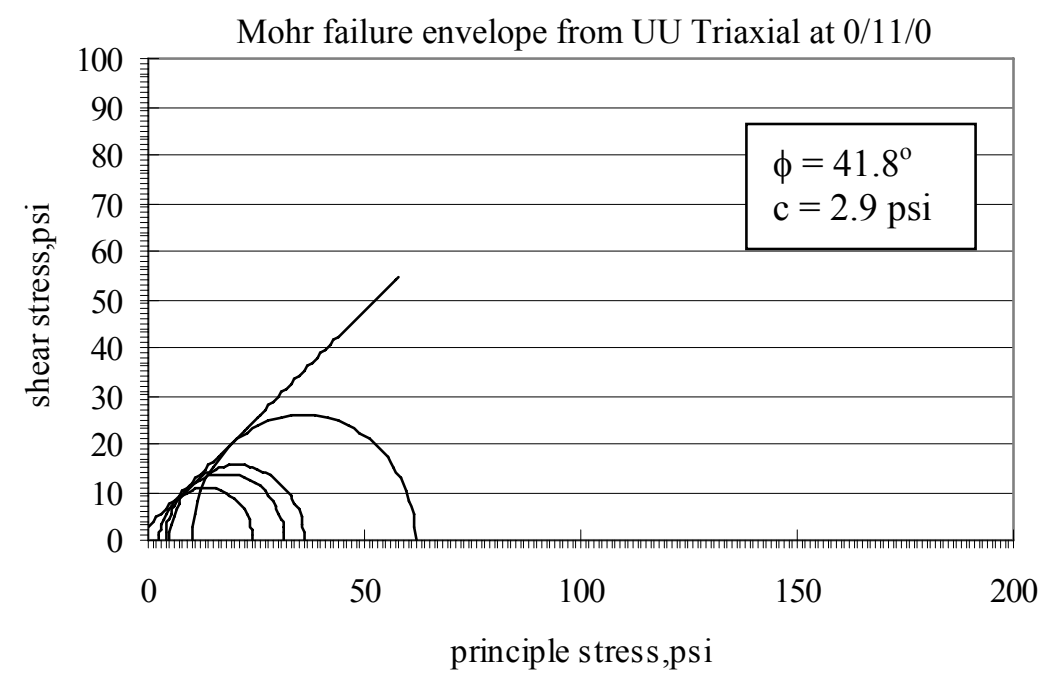

Figure 15: Deviatoric stress-axial strain response and Mohr failure envelope from soil samples prepared at a mixture of $0 / 11 / 0$ and subjected to UU Triaxial test. 

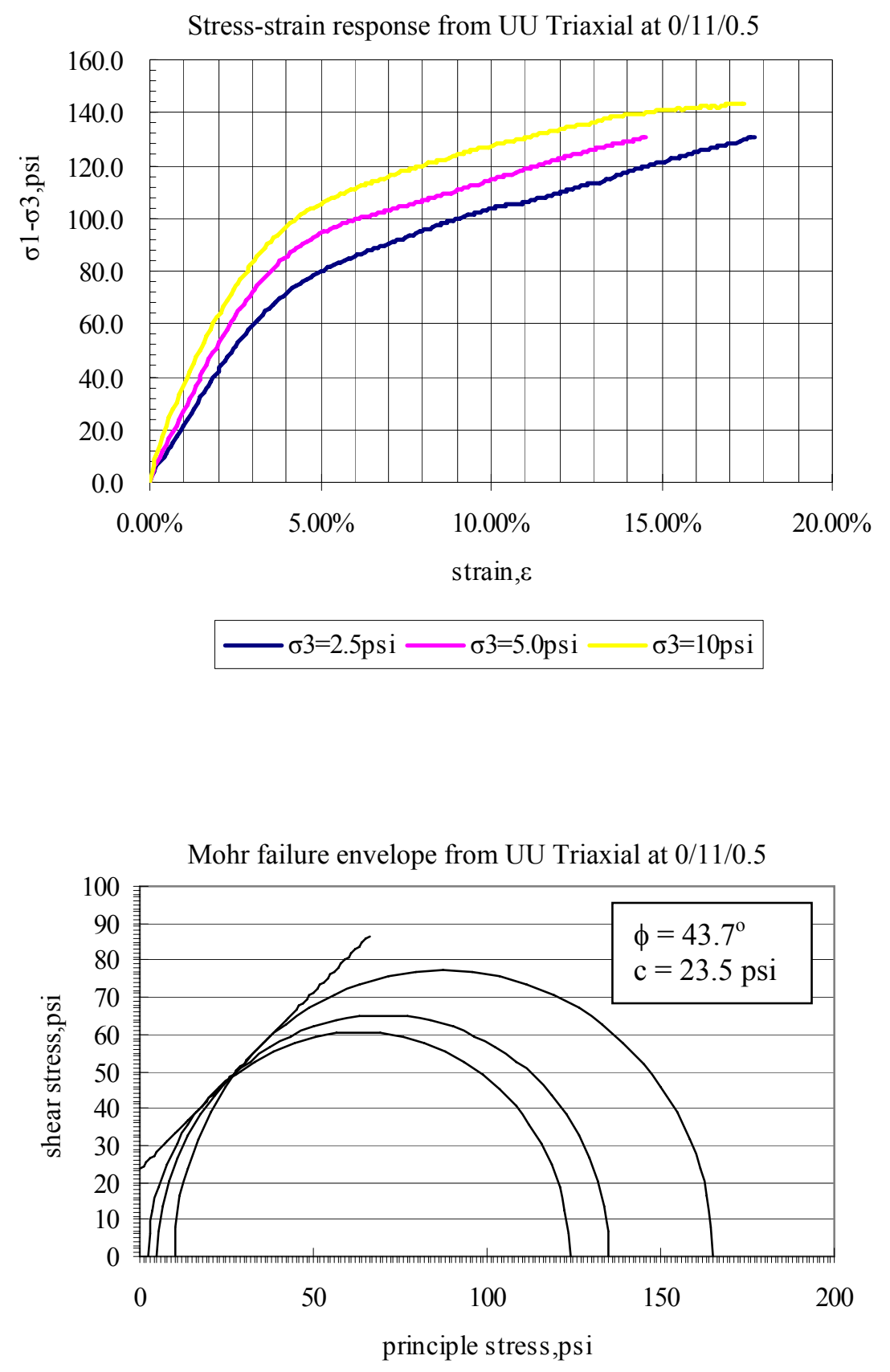

Figure 16: Deviatoric stress-axial strain response and Mohr failure envelope from soil samples prepared at a mixture of $0 / 11 / 0.5$ and subjected to UU Triaxial test. 

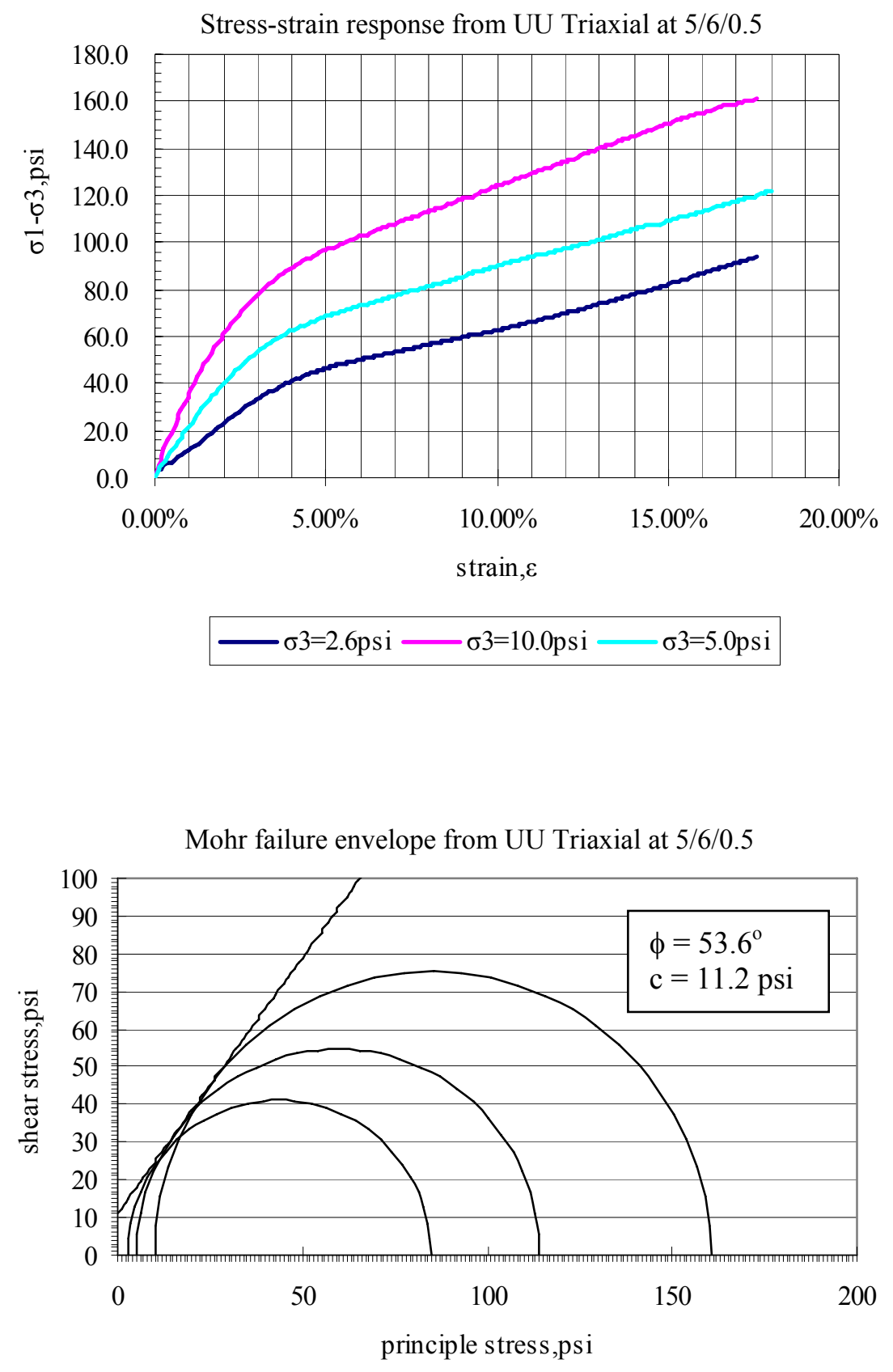

Figure 17: Deviatoric stress-axial strain response and Mohr failure envelope from soil samples prepared at a mixture of 5/6/0.5 and subjected to UU Triaxial test. 

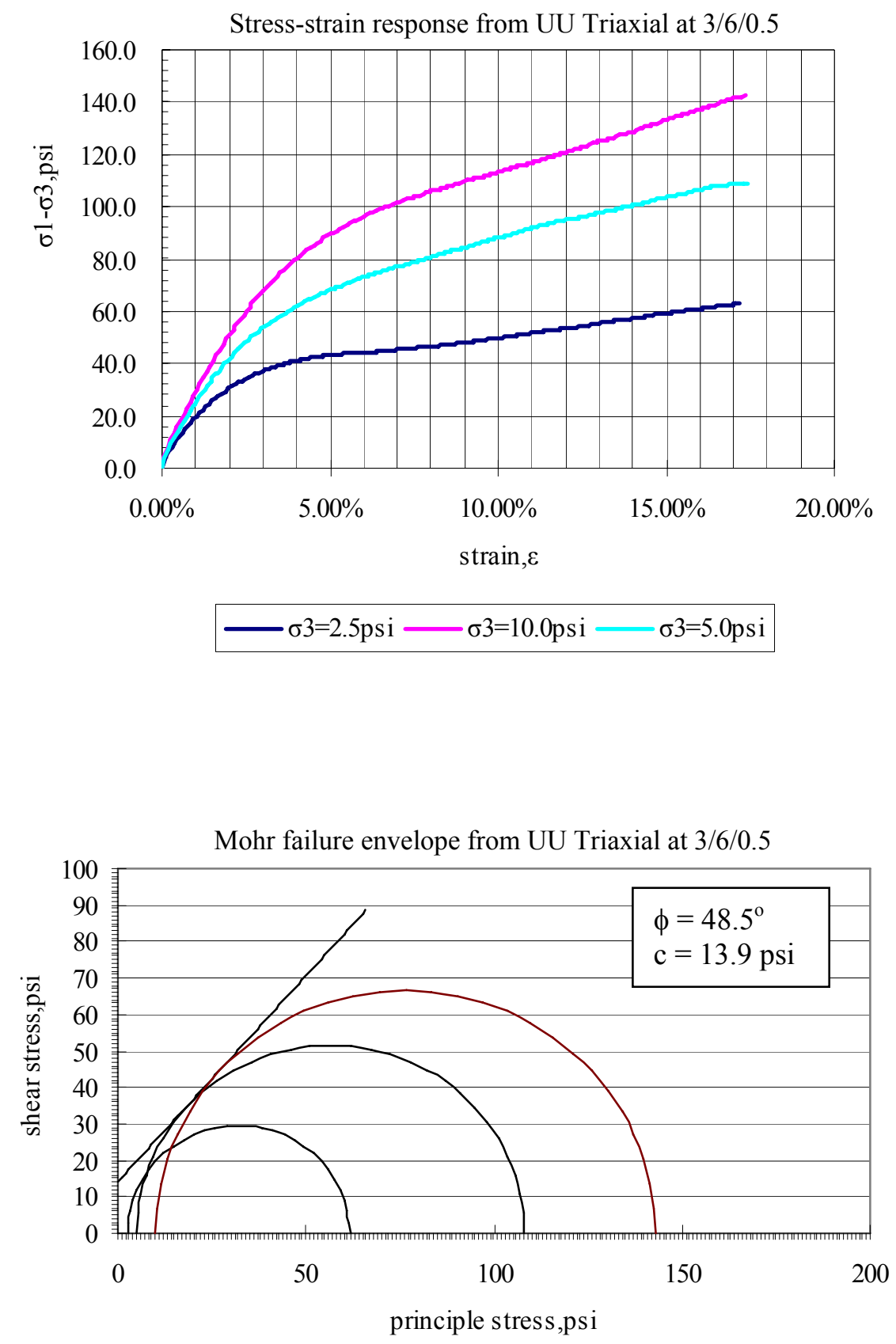

Figure 18: Deviatoric stress-axial strain response and Mohr failure envelope from soil samples prepared at a mixture of $3 / 6 / 0.5$ and subjected to UU Triaxial test. 

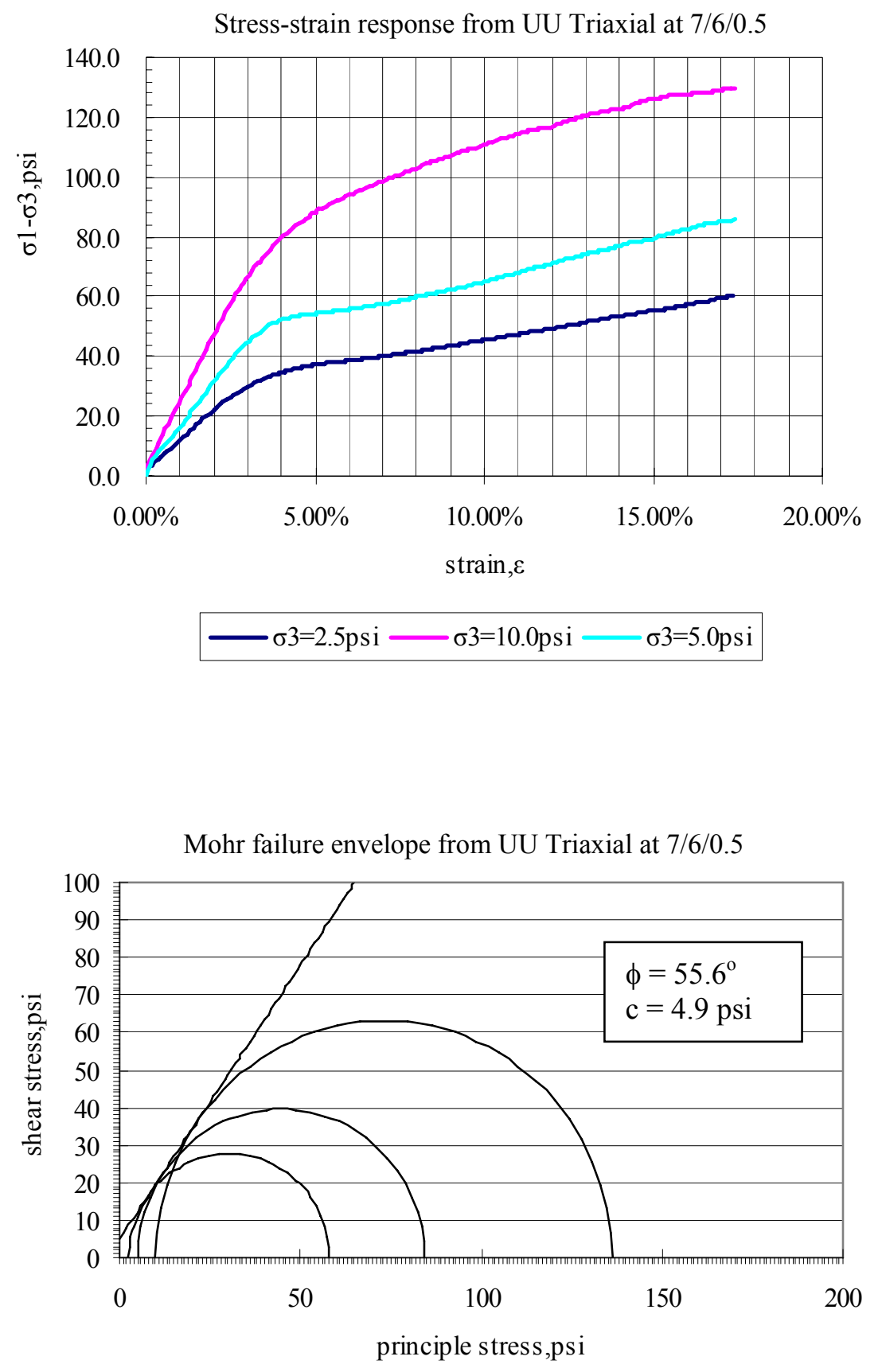

Figure 19: Deviatoric stress-axial strain response and Mohr failure envelope from soil samples prepared at a mixture of $7 / 6 / 0.5$ and subjected to UU Triaxial test. 


\subsection{Analysis of Findings and Discussion}

\subsection{CBR Testing}

Unless otherwise stated, the compactive effort for the following analysis is in accordance with ASTM D1557-02, as identified in Section 3.3. Analysis of test results where the non-standard compactive effort was used is identified as non-standard. CBR tests on unimproved native soil at the optimum moisture content (OMC) are used as a baseline for comparative purposes.

A comparison of the native soil mixed with water at the optimum moisture content and fiberreinforced soil mixed with water and geofibers at the OMC and optimum fiber content (OFC), respectively, appears in Figure 20. The fiber-reinforced soil appears to show a substantial improvement in CBR values over the unimproved soil, and the improvement appears to increase with deeper penetration. At the 0.100 inch depth of penetration, the improvement is $25 \%$; at 0.200 inch penetration, improvement is $102.5 \%$; and improvement continues up to $727.2 \%$ at 0.500 inch penetration.

Figures 21, 22 and 23 compare CBR values between samples with similar total liquid contents. In all three comparisons, test samples containing the synthetic fluid and water mixture appear to yield better results at the surface (i.e., 0.100 inch penetration) than samples mixed with water only. In Figure 21, the synthetic fluid sample showed a 36.7\% improvement over the water-only sample at the 0.100 inch penetration. In Figure 22, the improvement yielded by the synthetic fluid sample narrowed to $6.6 \%$.
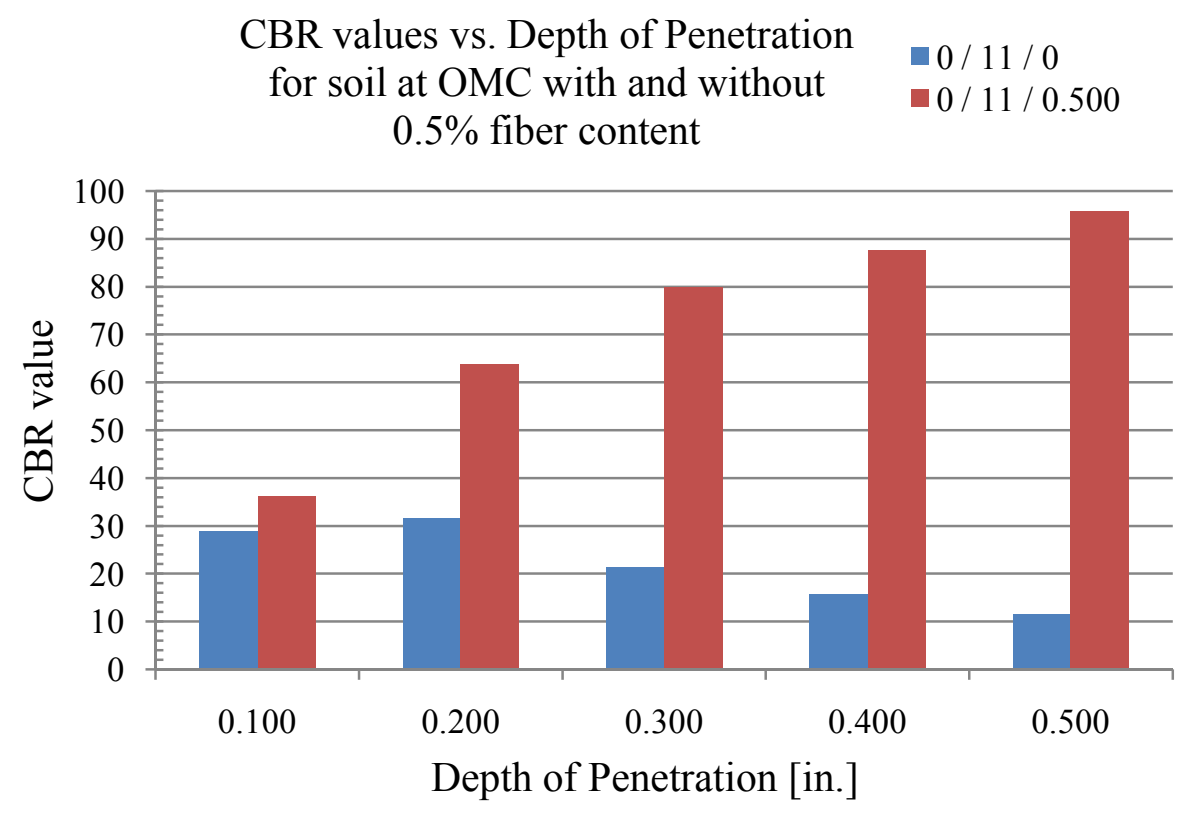

Figure 20: Comparison of CBR values between native soil samples with and without OFC. 


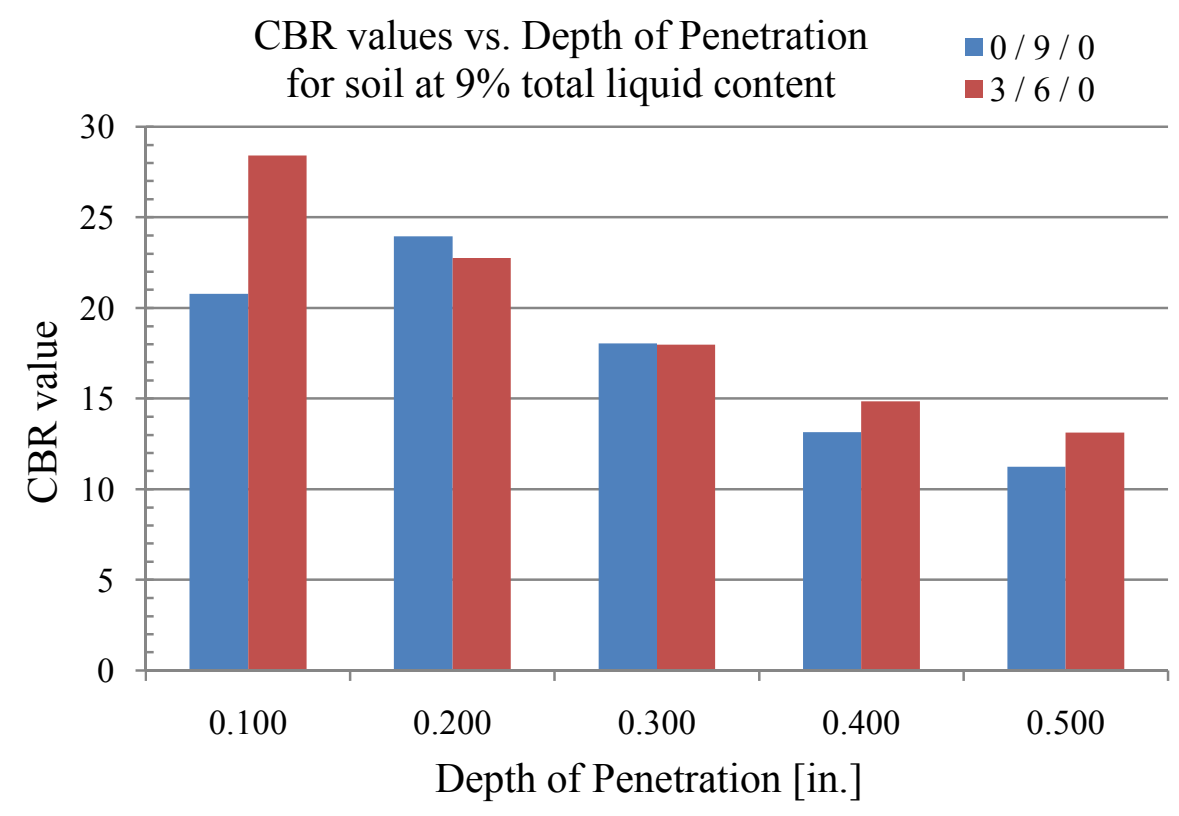

Figure 21: Comparison of CBR values between samples with a total liquid content of $9 \%$.

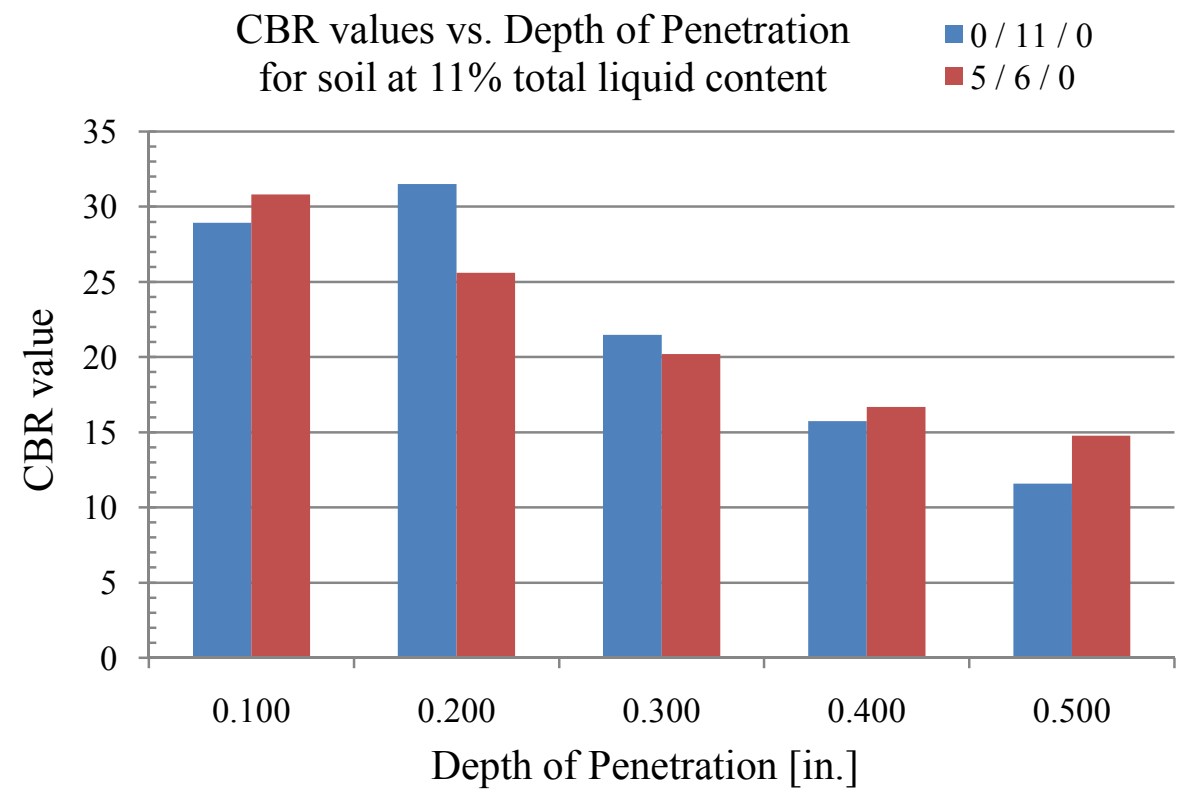

Figure 22: Comparison of CBR values between samples with a total liquid content of 11\%. 


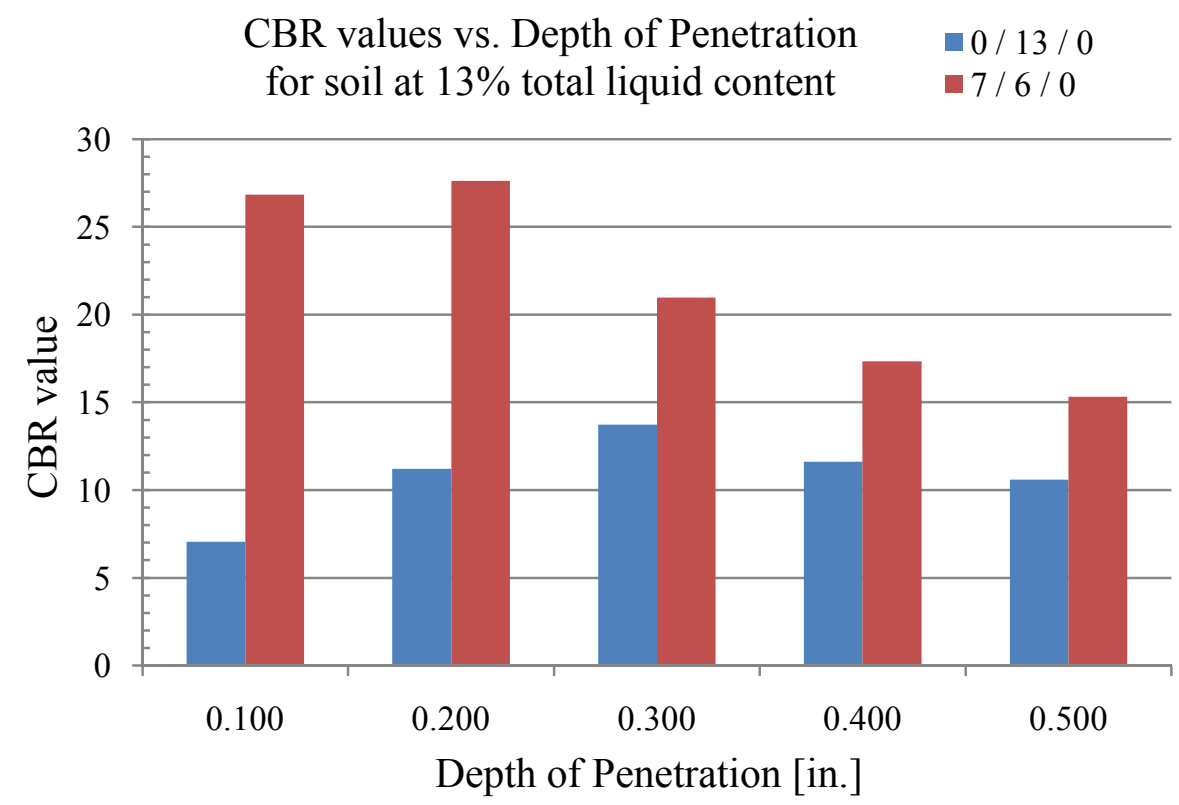

Figure 23: Comparison of CBR values between samples with a total liquid content of $13 \%$.

Test samples with total liquid contents above the OMC show significant improvement in samples containing the synthetic fluid and water mixtures, and a marked reduction in strength in the water-only samples. The synthetic fluid sample shows a $280.6 \%$ improvement over the sample with water at the 0.100 inch depth of penetration; improvement diminishes from $146.4 \%$ at the 0.200 inch depth of penetration to $44.8 \%$ at the 0.500 inch depth of penetration.

During compaction of the samples with $7 \%$ synthetic fluid and $6 \%$ water, no bleedout liquid was noted. This is a notable difference between the two samples with total liquid content of $13 \%$; there was substantial bleedout on the samples that contained $13 \%$ water. This suggests that the synthetic fluid reduces or restricts matrix water migration in the soil sample during compaction and CBR test penetration.

Soils stabilized by both geofibers and synthetic fluid with a total liquid content of $11 \%$ show notable improvement over the native soil sample at optimum moisture content. The soil with synthetic fluid and geofiber yielded CBR values lower than those for fiber-reinforced soil samples without the synthetic fluid. Figure 24 shows the relative CBR values between the test samples with a total liquid content of $11 \%$ of dry soil weight, with and without fiber. As noted from Figure 6, improvement of the native soil by adding geofibers, at the 0.200 inch depth of penetration, was 102.5\%. By comparison, in Figure 24, the improvement of the native soil by adding geofibers and synthetic fluid, at the same depth of penetration, is $20.6 \%$. 


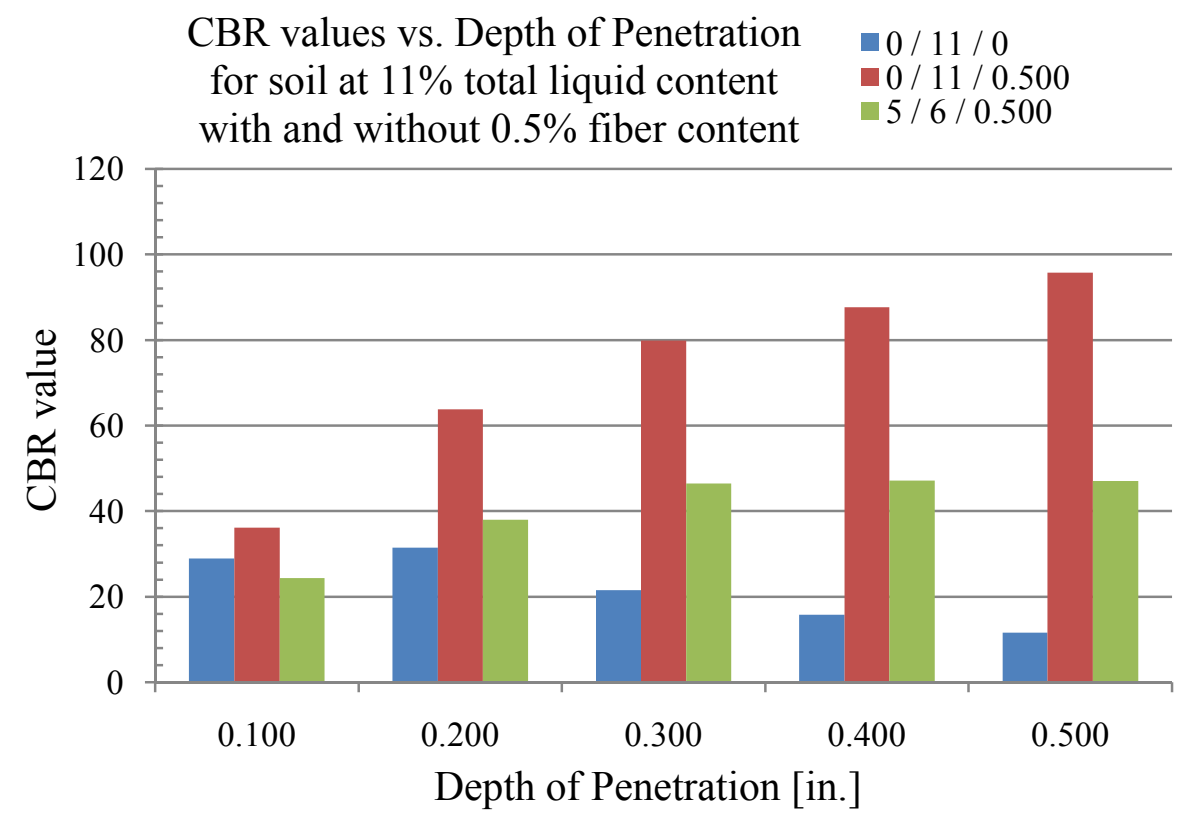

Figure 24: Comparison of CBR values between samples with synthetic fluid, water, and geofiber.

The effect of aging is presented in Figure 25. The aged samples provide insight into the benefits of synthetic fluid for soil stabilization to offset an apparent early bearing capacity reduction. As shown in Figure 25, the CBR values for the aged (by approximately 10 days) sample 5/6/0.500 appears higher than both the CBR values for the aged sample 0/11/0.500 and the CBR values for the aged sample. 5/6/0.500, Test data indicates that the improvement in the CBR value with aging, for the optimum combination of $5 / 6 / 0.500$ is on the order of $340 \%$ at 0.2 in. penetration and much larger improvements of CBR values were recorded at larger penetration depths. At the 0.500 inch depth of penetration, the estimated improvement shown after aging of the $5 / 6 / 0.500$ sample is $1007.4 \%$ of the non-aged, non-stabilized native soil sample " $0 / 11 / 0 "$.

Note that in Figure 25, the CBR value for the 0.500 inch penetration of the " $5 / 6 / 0.500$ " sample is an estimated value; the test load would have slightly exceeded the capacity of the test apparatus (i.e., greater than 10,000 lbf) and the test was stopped to prevent damage to the apparatus. A conservative value of $10,000 \mathrm{lbf}$ was used to calculate the bearing ratio at this data point. 


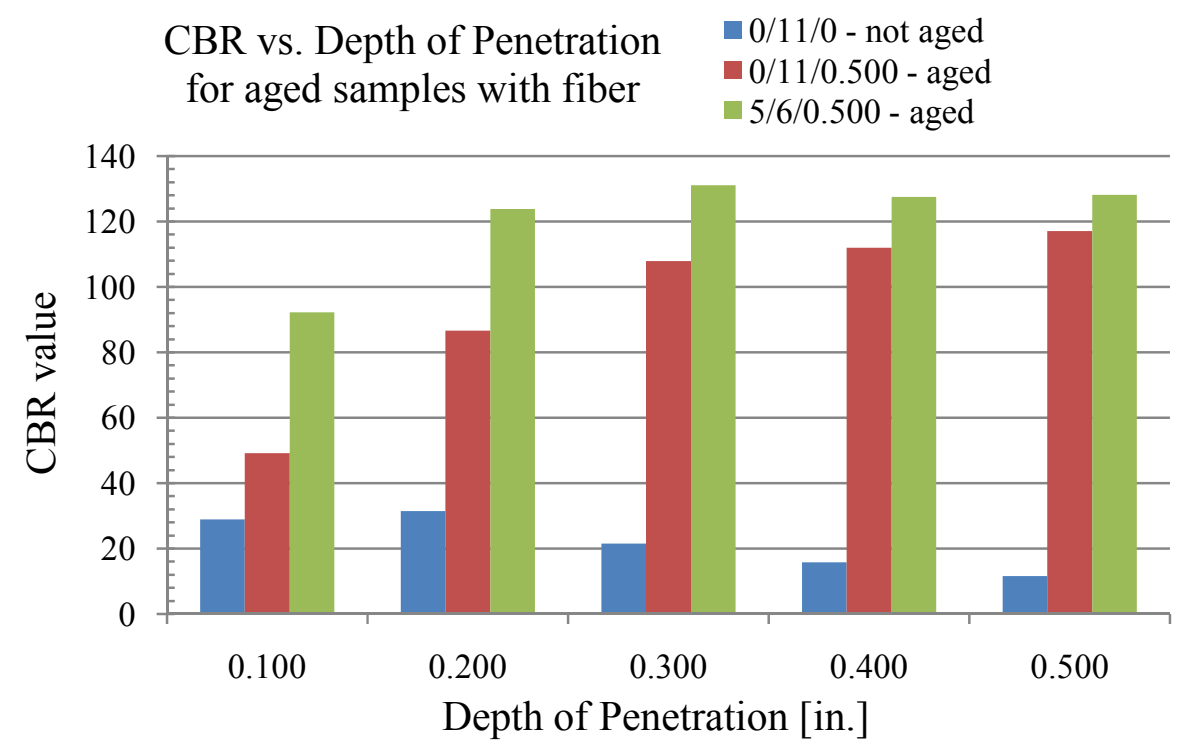

Figure 25: Comparison of CBR values between aged samples with fiber and the same total liquid content.

\subsection{Effect of Compactive Effort on Soil Improvement}

It is common in field applications to encounter lower compactive effort than specified. To address the effect of compactive effort on soil improvement, a series of CBR tests were performed on samples prepared with "non-standard" compactive effort. For the non-standard compactive effort, compaction was performed in accordance with ASTM D698-00a, except that a drop height of eighteen inches was used instead of twelve inches; the six-inch molds used conformed to the requirements of ASTM D698-00a. Thus, the compactive effort should correspond to somewhere between Standard Proctor and Modified Proctor. Detailed results were presented earlier in Section 3.3.5. Figure 26-a presents a comparison between the Modified Proctor and non-standard lower compactive efforts in terms of CBR tests performed on native soil samples at $11 \%$ moisture content. The impact of compactive effort is significantly pronounced at 0.2 inch penetration depth, indicating a CBR value of around 32 from the Modified Proctor versus 17 from the non-standard compaction. The samples prepared with Modifed Proctor have consistently resulted in higher CBR values for cases where the soil was improved with geofiber, as seen in Figure 26-b, and also with the addition of synthetic fluid, as displayed in Figure 26-c. These comparisons confirmed that the compactive effort plays as important a role as the stabilizing additives in improving the soil. 
NS: Non-standard low compactive effort

MDP: Modified Proctor compaction

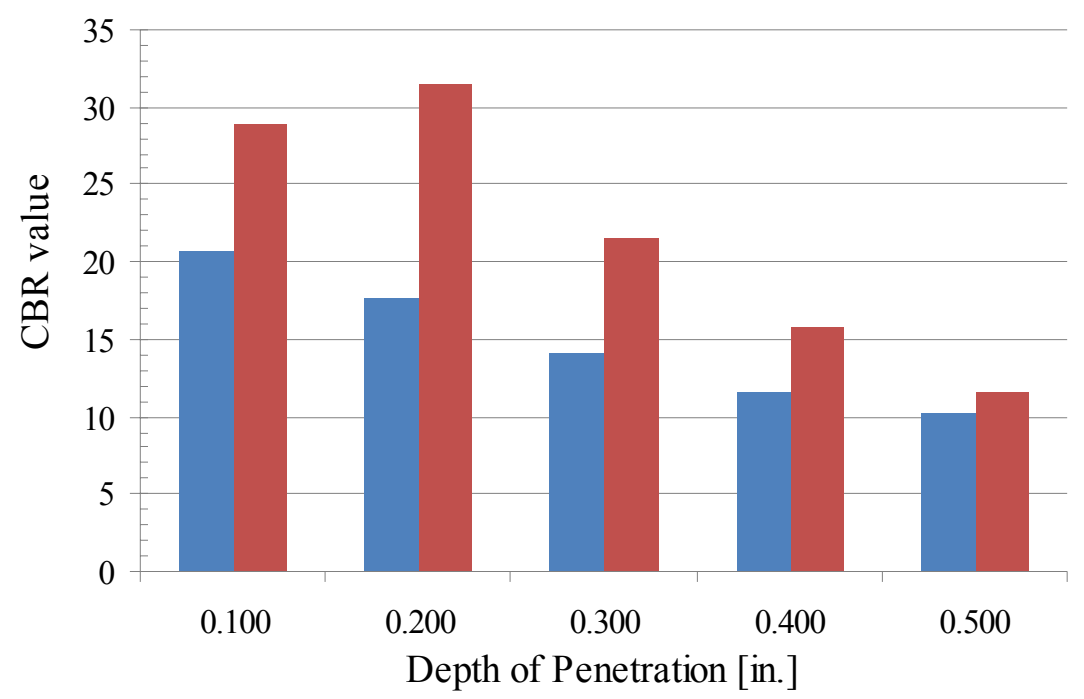

Figure 26-a: Non-standard versus Modified Proctor compactive efforts at 0/11/0.

NS: Non-standard low compactive effort

MDP: Modified Proctor compaction

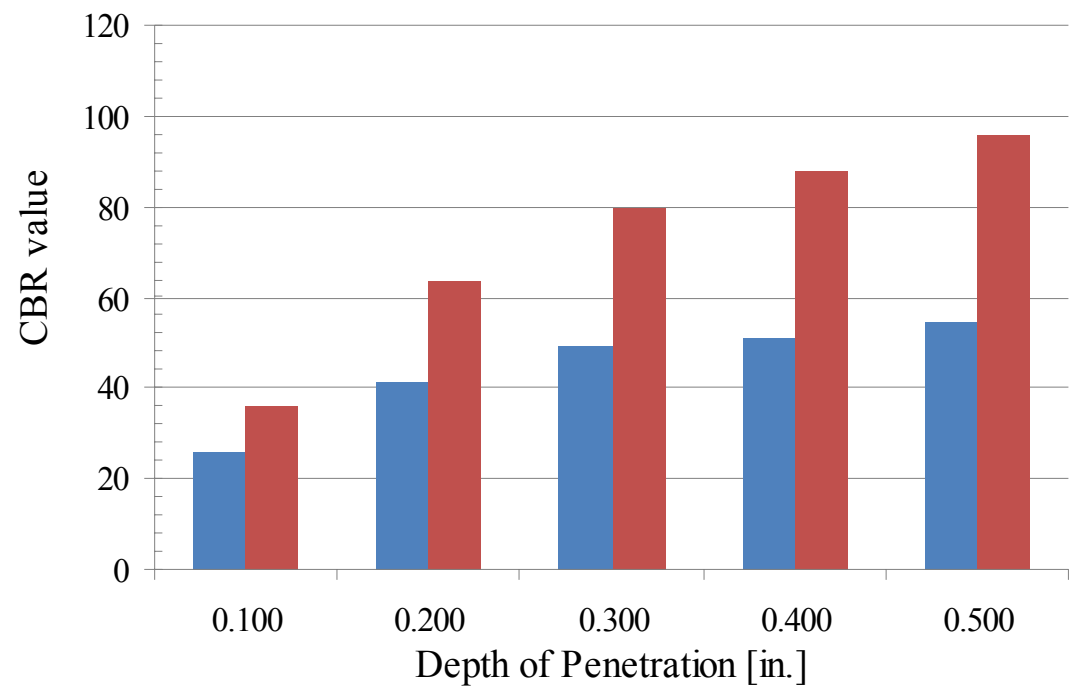

Figure 26-b: Non-standard versus Modified Proctor compactive efforts at 0/11/0.5. 
NS: Non-standard low compactive effort

MDP: Modified Proctor compaction

NS-5/6/0

- MDP-5/6/0

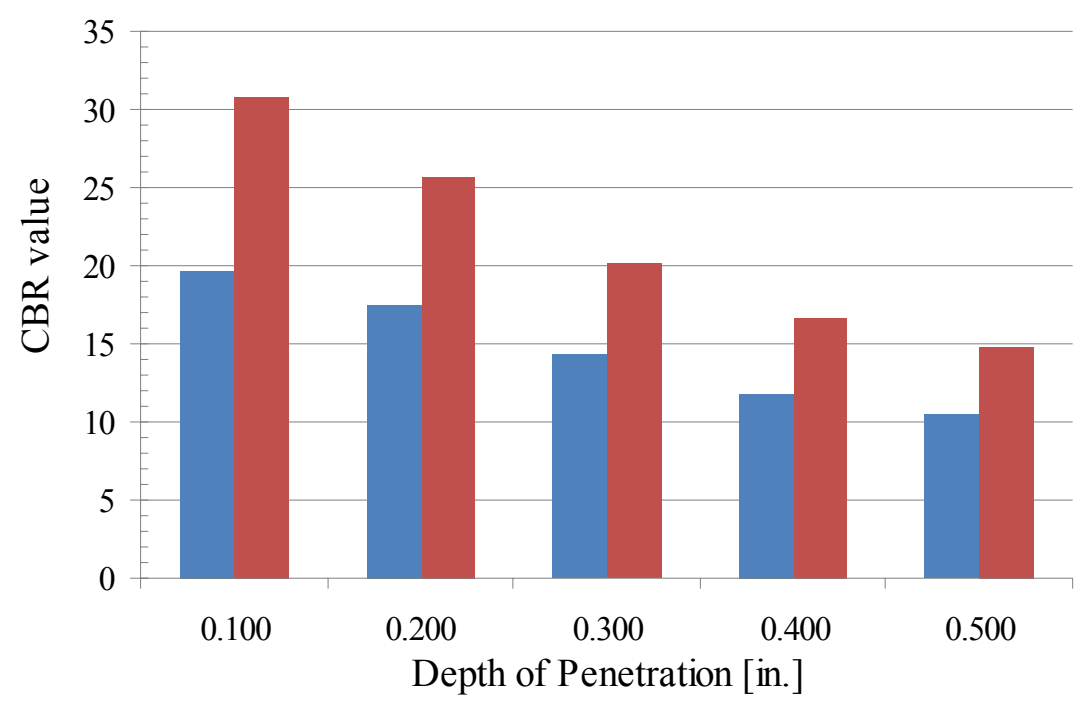

Figure 26-c: Non-standard versus Modified Proctor compactive efforts at 5/6/0

Figure 26: Comparison of CBR values between samples prepared with non-standard compactive effort and those prepared with Modfied Proctor.

\subsection{UU Triaxial Testing}

The results of UU triaxial testing were presented earlier in Section 3.4; below is a discussion of these results.

UU tiraxial compressive strength tests were performed on native soil samples compacted at OMC, geofiber-reinforced samples at OMC, and samples improved with a combination of geofiber and synthetic fluid. Three soil samples were prepared for each group, and each of these samples was tested at a different confining pressure. Comparison of the deviatoric stressaxial strain responses at each confining pressure is presented in Figure 27. This comparison provides valuable information about soil behavior. As can be seen, the unimproved native soil samples ("improvement" refers to geofiber reinforcement or addition of synthetic fluid) exhibit typical strain softening behavior past about 5\% axial strain with consistently lower strength than that of the improved samples. Soil improvement with either geofiber reinforcement or a combination of geofiber and synthetic fluid resulted in significant behavior changes. The improved soil was found to show strain hardening behavior, as opposed to the strain softening tendency apparent when unimproved. Additionally, at all confining pressures, the best performance was obtained from the geofiber-reinforced sample. The samples improved with a 
combination of geofiber reinforcement and synthetic fluid have more strength than the unimproved samples, yet less strength than those improved with geofiber only. The difference in strength between improved samples was found to be less pronounced at relatively a high confining pressure of 10 psi (see Figure 27-c).

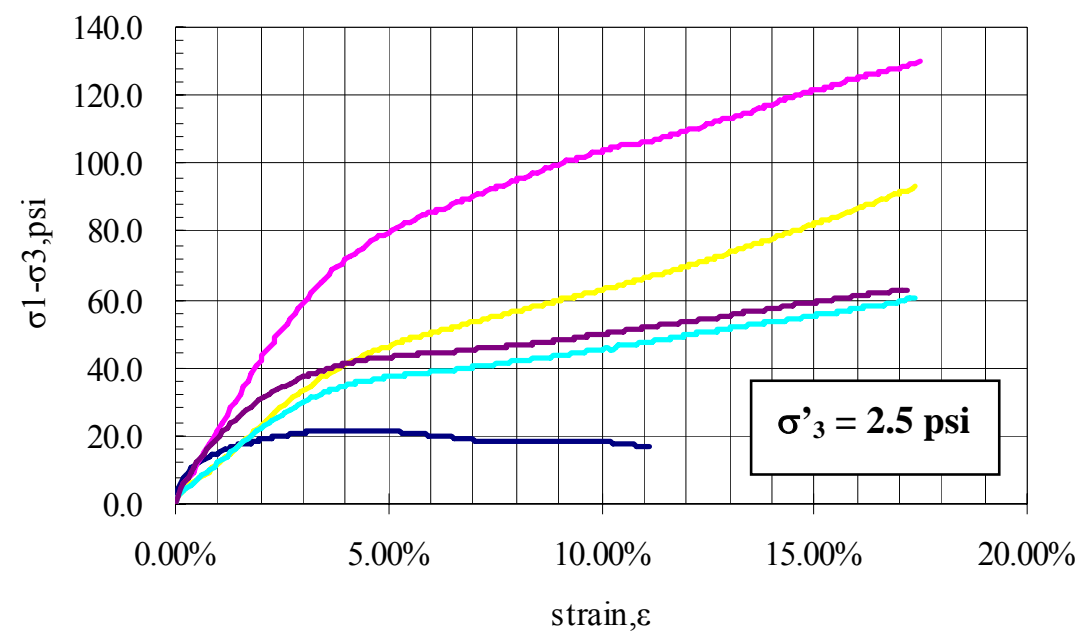

$-0 / 11 / 0-0 / 11 / 0.5-5 / 6 / 0.5$ note: $\mathrm{CP}=2.6 \mathrm{psi}-7 / 6 / 0.5-3 / 11 / 0.5$

Figure 27-a: UU Triaxial stress-strain response of various soil samples at 2.5 psi confining pressure.

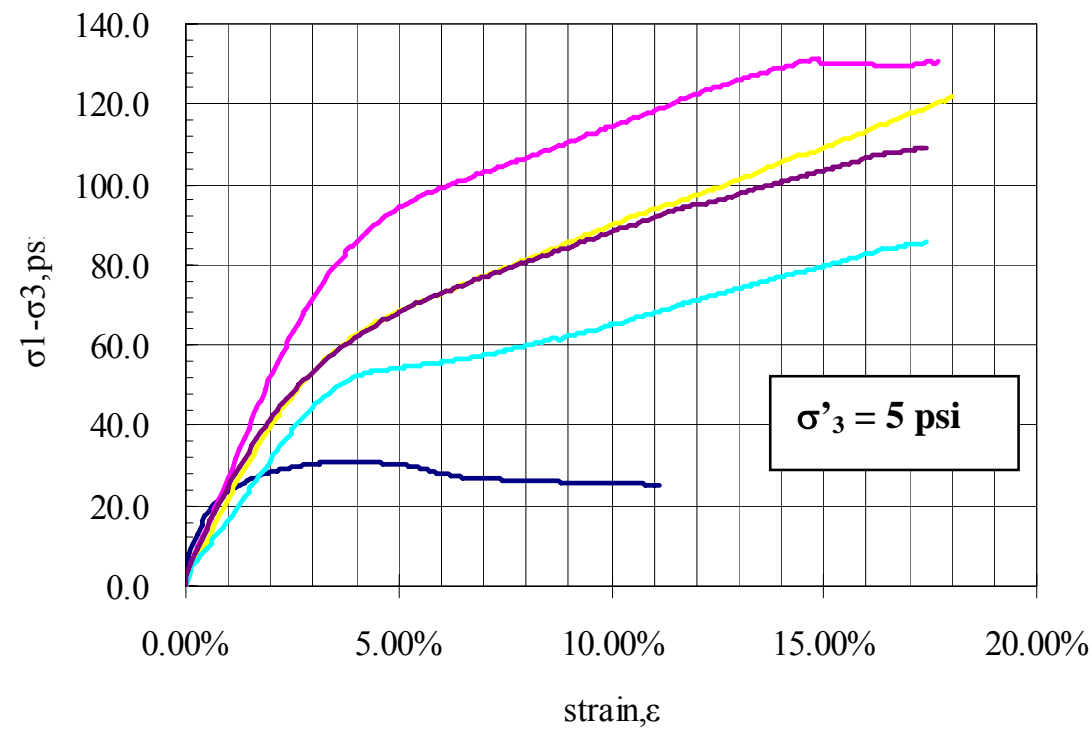

$-0 / 11 / 0-0 / 11 / 0.5-5 / 6 / 0.5$ note: $\mathrm{CP}=2.6 \mathrm{psi}-7 / 6 / 0.5-3 / 11 / 0.5$

Figure 27-b: UU Triaxial stress-strain response of various soil samples at 5 psi confining pressure. 


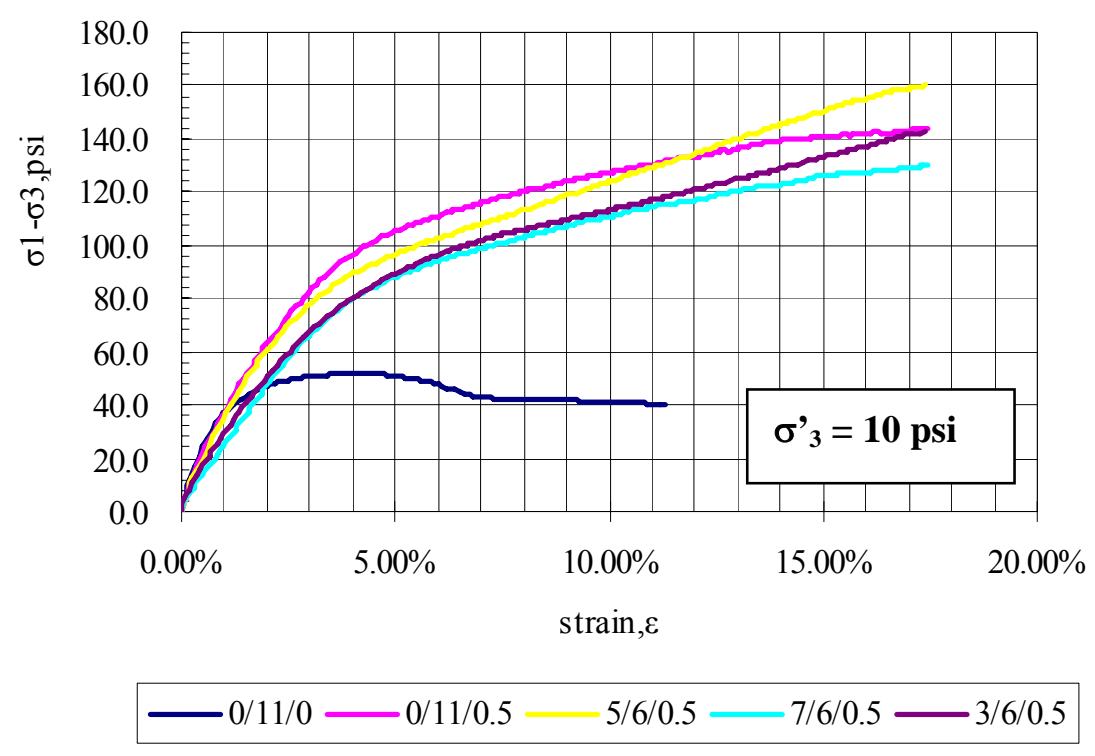

Figure 27-c: UU Triaxial stress-strain response of various soil samples at 10 psi confining pressure

Figure 27: Comparison of stress-strain responses from various soil samples subjected to UU Triaxial testing at different confining pressures.

It is important to note that the failure mechanisms of the improved and unimproved samples were different. Figure 28 displays two post-testing photos of failed samples for unimproved and geofiber-reinforced conditions. The failure of the unimproved soil sample shows a clear $45^{\circ}+\left(\phi^{\prime} / 2\right)$ failure plane whereas the geofiber-reinforced sample appears to fail by bulging, without a distinct failure plane. At large strains, geofibers appear to fully engage and prevent the occurrence of such failure plane.

The UU triaxial test results are summarized in Table 1. Unimproved samples prepared at OMC appeared to be the weakest among all the UU triaxial testing samples, with 2.9 psi cohesion and $41.8^{\circ}$ friction angle. The largest cohesion (23.5 psi) was obtained from the sample reinforced with geofiber only, where the friction angle was found to increase slightly to $43.7^{\circ}$. The largest friction angle $\left(55.6^{\circ}\right)$ occurred with the $7 / 6 / 0.500$ sample $(7 \%$ synthetic fluid content / $6 \%$ water content / $0.5 \%$ geofiber content). Based on the UU triaxial test results, one can argue that the optimum combination is $5 \%$ synthetic fluid content / $6 \%$ water content / $0.5 \%$ geofiber content. This combination was found to yield a cohesion of $11.2 \mathrm{psi}$ and a friction angle of $53.6^{\circ}$. 

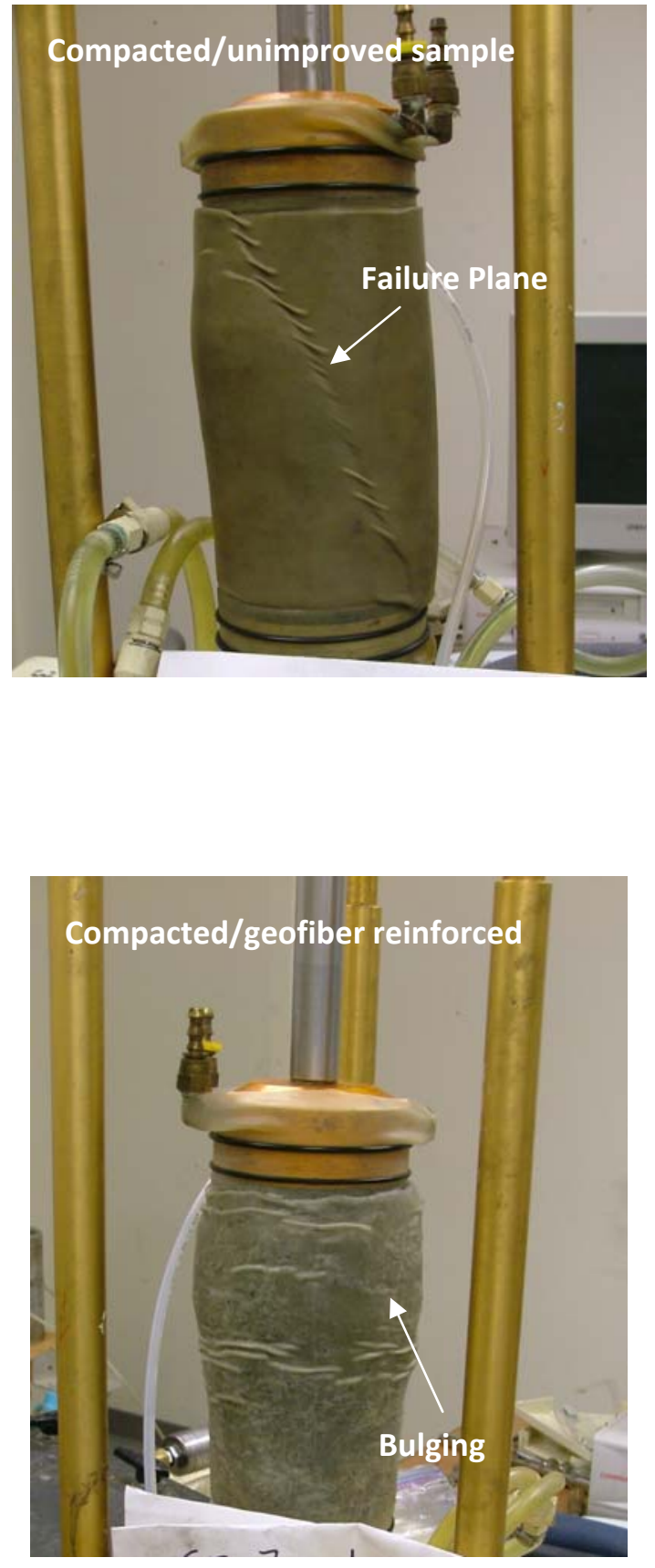

Figure 28: Failure mechanisms of unimproved and improved soil samples. 
Table 1: Summary of the UU Triaxial Test Results

\begin{tabular}{|c|c|c|c|c|}
\hline $\begin{array}{c}\text { Synthetic } \\
\text { Fluid } \\
\text { Content,\% }\end{array}$ & $\begin{array}{c}\text { Water } \\
\text { Content, \% }\end{array}$ & $\begin{array}{c}\text { Geofiber } \\
\text { Content, } \%\end{array}$ & $\begin{array}{c}\text { Friction Angle, } \\
\text { degrees }\end{array}$ & Cohesion, psi \\
\hline- & 11 & - & 41.8 & 2.9 \\
\hline- & 11 & 0.5 & 43.7 & 23.5 \\
\hline 5 & 6 & 0.5 & 53.6 & 11.2 \\
\hline 3 & 6 & 0.5 & 48.5 & 13.9 \\
\hline 7 & 6 & 0.5 & 55.6 & 4.9 \\
\hline
\end{tabular}




\subsection{Conclusions}

The improvement of the silty sand collected from Bethel, Alaska with the additions of the stabilizers (geofiber and synthetic fluid) discussed above was evaluated in the laboratory through CBR and UU triaxial compression tests.

The conclusions from this research are:

- Bethel silty sand was found to have an optimum moisture (water) content of $11 \%$.

- $\quad$ The CBR value at optimum moisture content without stabilizers was found to be 31 (at 0.2 in penetration). This CBR value falls within the typical range (20-40) for SM type silty sand.

- The optimum geofiber content, which corresponds to the largest CBR value, appears to be about $0.5 \%$. Lower or higher geofiber contents resulted in lower CBR values.

- Addition of $0.5 \%$ geofiber at optimum moisture content of $11 \%$ increased the CBR value from 31 to 62 at 0.2 in. penetration and to much higher values at larger penetrations. Thus, the improvement in the CBR values by adding $0.5 \%$ geofiber to the soil was $100 \%$ and above. In terms of CBR values, the geofiber-reinforced (improved) soil appears to be in the range of well-graded gravel or sandy gravel, for which the CBR ranges from 60 to 80 .

- In an effort to determine the optimum synthetic fluid content, it was found that the synthetic fluid would only work when used with some original moisture (water) in the soil. The optimum combination of synthetic fluid content / water content was found to be $5 \% / 6 \%$. It is also important to note that the total liquid content in the soil in this case is $11 \%$, which is equal to the moisture content determined for the native (no stabilizer added) soil.

- Addition of the synthetic fluid alone did not provide a noticeable improvement in the CBR values. In general, the CBR values obtained from the soil samples improved with synthetic fluid were very similar to those obtained from unimproved soil samples at optimum moisture content.

- The compactive effort appears to play a significant role in the effectiveness of the stabilizers, especially for the geofiber. Increasing the compactive effort from a non-standard low to Modified Proctor appeared to result in 50\% higher CBR values. This leads to the conclusion that these soil stabilizers will be best utilized with sufficient compactive effort.

- The study of soil-strength characteristics through UU triaxial compression tests indicated a friction angle of $41.8^{\circ}$ and a slight cohesion of 2.9 psi from native (no stabilizer added) soil samples compacted (Modified Proctor) at the optimum moisture content of $11 \%$. When $0.5 \%$ geofiber was added to the soil, the cohesion increased significantly, from 2.9 psi to $23.5 \mathrm{psi}$, while the friction angle increased by about $2^{\circ}$ only. However, the addition of synthetic fluid along with geofiber showed a less pronounced increase in cohesion with a more significant improvement in the friction angle. The cohesion and friction angle for this case were $11.2 \mathrm{psi}$ and $53.6^{\circ}$, respectively.

- The UU triaxial compression tests showed the failure mode changes from a distinct $45^{\circ}+\left(\phi^{\prime} / 2\right)$ failure plane for unimproved soil samples to a bulging-type failure with no distinct failure plane in the case of geofiber-reinforced soil samples (dilative to contractive).

- Based on the results of both CBR and UU triaxial compression tests, to get the best performance from the Bethel silty sand, the optimum combination of synthetic fluid content / moisture content / geofiber content appears to be $5 \% / 6 \% / 0.5 \%$. 
- Aging soil samples by approximately 10 days yielded a further significant improvement in the CBR values. The improvement in the CBR value with aging, for the optimum combination of $5 \% / 6 \% / 0.5 \%$ was found to be on the order of $340 \%$; the CBR increased from 36 (in the case of a non-aged sample) to 124 (in the case of an aged sample). 


\subsection{Future Research}

Based on this limited laboratory effort, it is clear that the geofiber and synthetic fluid can significantly increase the strength and bearing capacity of the Bethel silty sand. However, to better evaluate the effectiveness of these stabilizing materials further research is needed. This future research should focus on: (1) long term stability of soils through freeze/thaw cycles, (2) more indepth investigation on the aging effect, (3) low temperature workability, (4) stability evaluation through resilient modulus testing, (5) field performance testing, (6) testing of various soil types from different parts of Alaska or potentially other states, and (7) combinations of different geofibers and fluid additives, including soil cement. 


\subsection{References}

Brangan, D., and Todd Hawkins, "Innovative Earth Friendly Soil Stabilization Solutions." PowerPoint presentation. CD-ROM. Peak Civil Technologies. 16 Apr 2007.

Connor, B. Personal communication 16 July 2007.

Hawkins, T. Personal communication 16 July 2007.

Scholen, D.E. Nonstandard Stabilizers. Report FHWA-FLP-92-011, Federal Highway Administration, Washington, D.C., July 1992, 113 pages. 


\section{Appendix A - Test Data}

Table A.1: Sieve Analysis data.

\begin{tabular}{|c|c|c|c|}
\hline Sample 1 & \multicolumn{3}{|c|}{ Bethel Silty Sand } \\
\hline $\begin{array}{l}\text { Sieve } \\
\text { No. }\end{array}$ & $\begin{array}{l}\text { Particle } \\
\text { Size } \\
{[\mathrm{mm}]}\end{array}$ & $\begin{array}{l}\text { Cumulative } \\
\text { Retained } \\
{[\mathrm{g}]}\end{array}$ & $\begin{array}{l}\% \\
\text { passed }\end{array}$ \\
\hline 4 & 4.75 & 0 & 100 \\
\hline 16 & 1.18 & 0.1 & 100 \\
\hline 30 & 0.6 & 1.4 & 100 \\
\hline 50 & 0.3 & 47.7 & 95 \\
\hline 100 & 0.147 & 460.6 & 54 \\
\hline 140 & 0.106 & 677.4 & 33 \\
\hline 200 & 0.075 & 877.5 & 12.7 \\
\hline pan & 0 & 1005.4 & 0.00 \\
\hline start & & 1005.4 & \\
\hline
\end{tabular}

\begin{tabular}{|r|r|r|r|}
\hline Sample 2 & \multicolumn{3}{|c|}{ Bethel Silty Sand } \\
\hline & $\begin{array}{l}\text { Particle } \\
\text { Size } \\
\text { Sieve No. }\end{array}$ & $\begin{array}{l}\text { lmulative } \\
\text { Retained } \\
{[\mathrm{g}]}\end{array}$ & \multicolumn{1}{l}{$\begin{array}{l}\text { lo } \\
\text { passed }\end{array}$} \\
\hline 4 & 4.75 & 0 & 100 \\
\hline 16 & 1.18 & 0.1 & 100 \\
\hline 30 & 0.6 & 1.7 & 100 \\
\hline 50 & 0.3 & 51.3 & 95 \\
\hline 100 & 0.147 & 472.3 & 53 \\
\hline 140 & 0.106 & 673.7 & 33 \\
\hline 200 & 0.075 & 864.5 & 13.8 \\
\hline pan & 0 & 1002.6 & -0.02 \\
\hline & & 1002.4 & \\
\hline start & & & \\
\hline
\end{tabular}

Table A.2: Optimum Moisture Content data.

\begin{tabular}{|r|r|}
\hline $\begin{array}{l}\text { Moisture } \\
\text { Content } \\
{[\%]}\end{array}$ & $\begin{array}{l}\text { Dry } \\
\text { Density } \\
\text { [pcf] }\end{array}$ \\
\hline 0.0 & 114.7 \\
\hline 2.5 & 107.4 \\
\hline 4.3 & 109.3 \\
\hline 6.3 & 108.4 \\
\hline 8.3 & 109.1 \\
\hline 9.9 & 108.6 \\
\hline 11.2 & 110.8 \\
\hline 12.6 & 109.2 \\
\hline 14.2 & 107.6 \\
\hline 16.8 & 105.0 \\
\hline 19.5 & 102.8 \\
\hline
\end{tabular}


Table A.3: Optimum Synthetic Fluid Content data.

\begin{tabular}{|l|l|l|}
\hline $\begin{array}{l}\text { SFC } \\
\text { SF }\end{array}$ & $\begin{array}{l}\text { MC } \\
\text { Mpcf] }\end{array}$ & $\begin{array}{l}\text { Density } \\
\text { [pry }\end{array}$ \\
\hline 3.0 & 8.0 & 110.5 \\
\hline 7.0 & 4.0 & 110.5 \\
\hline 0.0 & 0.0 & 114.7 \\
\hline 0.3 & 0.0 & 115.0 \\
\hline 0.6 & 0.0 & 111.8 \\
\hline 0.9 & 0.0 & 110.7 \\
\hline 1.3 & 0.0 & 108.7 \\
\hline 1.5 & 0.0 & 108.1 \\
\hline 1.9 & 0.0 & 107.0 \\
\hline 2.5 & 0.0 & 107.5 \\
\hline 3.2 & 0.0 & 107.5 \\
\hline 3.8 & 0.0 & 107.2 \\
\hline 4.4 & 0.0 & 108.2 \\
\hline 5.0 & 0.0 & 107.8 \\
\hline 5.7 & 0.0 & 107.9 \\
\hline & & \\
\hline
\end{tabular}

Table A.4: Initial Optimum Fiber Content data (from four-inch diameter molds).

\begin{tabular}{|c|c|}
\hline \% Fiber & $\begin{array}{l}\text { Dry } \\
\text { Density } \\
\text { [pcf] }\end{array}$ \\
\hline 0.15 & 110.2 \\
\hline 0.19 & 109.5 \\
\hline 0.30 & 109.4 \\
\hline 0.62 & 108.7 \\
\hline 1.03 & 108.5 \\
\hline 1.18 & 103.8 \\
\hline 1.45 & 102.7 \\
\hline 2.20 & 99.8 \\
\hline 3.22 & 92.0 \\
\hline
\end{tabular}


Table A.5: Average Dry Densities from CBR tests (six-inch molds).

\begin{tabular}{|r|r|r|r|}
\hline $\begin{array}{l}\text { Avg. Dry } \\
\text { Density } \\
\text { [pcf] }\end{array}$ & \% SFC & \multicolumn{2}{|l|}{} \\
\hline 105.9 & 0 & 8.8 & 0 \\
\hline 107.9 & 0 & 10.9 & 0 \\
\hline 105.5 & 0 & 12.1 & 0 \\
\hline 104.9 & 0 & 12.6 & 0 \\
\hline 109.9 & 3.0 & 6.0 & 0 \\
\hline 113.0 & 5.0 & 6.0 & 0 \\
\hline 116.1 & 7.0 & 6.0 & 0 \\
\hline 109.2 & 0 & 10.8 & 0.375 \\
\hline 110.5 & 0 & 10.2 & 0.500 \\
\hline 108.8 & 0 & 10.3 & 0.625 \\
\hline 109.0 & 3.0 & 6.0 & 0.500 \\
\hline 108.6 & 5.0 & 6.0 & 0.500 \\
\hline 108.8 & 7.0 & 6.0 & 0.500 \\
\hline
\end{tabular}

a: If a specific fluid content is specified, the dry density, synthetic fluid content and moisture content are estimates. If the value of \% $\mathrm{SFC}$ is zero, the moisture content was found by drying the sample and the dry density was calculated from the moisture content.

Table A.6: Average CBR values.

\begin{tabular}{|r|r|r|r|r|r|r|r|r|r|r|r|r|}
\hline SFC/MC/F & $0 / 9 / \mathrm{X}^{\mathrm{a}}$ & \multicolumn{4}{|c|}{$0 / 11 / \mathrm{X}^{\mathrm{a}}$} & $0 / 13 / \mathrm{X}^{\mathrm{a}}$ & \multicolumn{2}{|c|}{$3 / 6 / \mathrm{X}^{\mathrm{a}}$} & \multicolumn{3}{|c|}{$5 / 6 / \mathrm{X}^{\mathrm{a}}$} & \multicolumn{2}{|c|}{$7 / 6 / \mathrm{X}^{\mathrm{a}}$} \\
\hline Depth [in.] & 0 & 0 & 0.375 & 0.500 & 0.625 & 0 & 0 & 0.500 & 0 & 0.500 & 0 & 0.500 \\
\hline 0.100 & 20.8 & 28.9 & 30.5 & 36.2 & 29.4 & 7.1 & 28.4 & 25.8 & 30.8 & 24.4 & 26.9 & 28.9 \\
\hline 0.200 & 24.0 & 31.5 & 47.8 & 63.8 & 54.4 & 11.2 & 22.8 & 40.6 & 25.6 & 38.0 & 27.6 & 45.3 \\
\hline 0.300 & 18.1 & 21.5 & 51.2 & 79.9 & 70.8 & 13.7 & 18.0 & 51.2 & 20.2 & 46.4 & 21.0 & 55.9 \\
\hline 0.400 & 13.2 & 15.7 & 48.3 & 87.6 & 76.4 & 11.6 & 14.8 & 57.6 & 16.7 & 47.1 & 17.3 & 60.4 \\
\hline 0.500 & 11.2 & 11.6 & 34.0 & 95.8 & 82.9 & 10.6 & 13.1 & 64.4 & 14.8 & 47.0 & 15.3 & 66.2 \\
\hline
\end{tabular}

a: The " $X$ " in the sample name is a variable for fiber content. The row immediately below the sample name contains the percentage of fiber content, and CBR values for that sample are in the column below the fiber content value.

Table A.7: CBR values for aged samples.

\begin{tabular}{|l|r|r|r|r|}
\hline $\begin{array}{l}\text { Depth } \\
\text { [in.] }\end{array}$ & $3 / 6 / 0.5$ & $5 / 6 / 0.5$ & $7 / 6 / 0.5$ & $0 / 11 / 0.5$ \\
\hline 0.100 & 86.2 & 92.2 & 60.3 & 49.2 \\
\hline 0.200 & 106.6 & 123.8 & 78.5 & 86.6 \\
\hline 0.300 & 109.1 & 131.1 & 97.1 & 107.9 \\
\hline 0.400 & 108.0 & 127.6 & 111.2 & 111.9 \\
\hline 0.500 & 115.3 & 128.2 & 124.9 & 117.1 \\
\hline
\end{tabular}




\section{Appendix B - FiberSoils GEOFIBER ${ }^{\circledR}$ 3627BT Product Data}

The following product data is provided by FiberSoils LLC:

Product:

Description:

Materials:

\section{Product Specification}

\section{GEOFIBERS $^{\circledR}$ 3627BT}

Polypropylene tape fibers for soil reinforcement.

Discrete polypropylene tape fibers shall be inert and shall conform to the following properties:

\begin{tabular}{|c|c|c|}
\hline Property & Test Method & Requirement \\
\hline Polypropylene & ASTM D4101 \\
& Group 1/Class 1/ Grade 2 & $99 \%$ Minimum \\
\hline Moisture Absorption & ----- & Nil \\
\hline Fiber Length & Measured & 2.75 inch, minimum \\
\hline Aspect Ratio & Measured/Calculated & 260 minimum \\
\hline Color & ----- & Black \\
\hline Specific Gravity & ASTM D792 & $0.91 \mathrm{gm} / \mathrm{cm}^{3}$ \\
\hline Carbon Black Content & ASTM D1603 & $0.6 \%$, minimum \\
\hline Tensile Strength & ASTM D2256 & $40,000 \mathrm{psi}$ minimum \\
\hline Tensile Elongation & ASTM 2256 & $15 \%$, maximum \\
\hline Young's Modulus & ASTM D2101 & $600,000 \mathrm{psi}$ minimum \\
\hline
\end{tabular}

Packaging and Storage: $\quad$ The fibers shall be packaged in sealed polypropylene bags placed in cardboard or other suitable cartons. The cartons shall be properly identified with a clearly readable label. The label should list the following information:

a. A unique carton number,

b. Name of fiber manufacturer,

c. Product brand name and style designation (if applicable),

d. Fiber length,

e. Net weight of fiber in each carton.

Store the fiber cartons in a manner to protect the fibers from moisture and direct sunlight. 


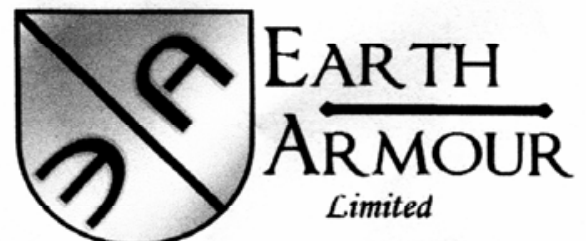

\section{TECHNical Data SheET}

\section{Product Name: Earth Armour - Arctic}

Description: Earth Armour - Arctic is a cold-region soil stabilization and dust control liquid, which does not require any water, for construction and maintenance of roads, construction sites, helipads, and gravel runways. It is an environmentally friendly synthetic liquid, which is non-toxic and safe for human, animal and plant life. Earth Armour - Arctic functions as both a densification and ballasting agent. Coating and lubricating soil particles assures complete compaction, cohesion resulting maximum bearing strength. Earth Armour - Arctic also functions as a ballasting agent effectively weighing down dust particles preventing them from becoming airborne. It does not create housekeeping problems such as tracking onto roadways or damaging equipment and vehicles.

\begin{tabular}{|c|c|c|}
\hline \multicolumn{3}{|c|}{ Typical Performance Data } \\
\hline \multirow[b]{2}{*}{ Test Description } & \multirow[b]{2}{*}{ ASTM NO. } & Product Name \\
\hline & & $\begin{array}{l}\text { Earth Armour - Arctic } \\
\text { (Synthetic liquid) }\end{array}$ \\
\hline Specific Gravity @ 60\% $60^{\circ} \mathrm{F}$ & D 1298 & 0.863 \\
\hline Gravity, ${ }^{\circ} \mathrm{API} @ 60^{\circ} \mathrm{F}$ & D 287 & 32.4 \\
\hline Density (Lb/Gal) @ 60F & D 287 & 7.2 \\
\hline Viscosity, SSU @ $100^{\circ} \mathrm{F}$ & D 88 & 52 \\
\hline Viscosity, SSU @ 210 $\mathrm{F}$ & D 88 & 33 \\
\hline Viscosity, cSt @ $40^{\circ} \mathrm{C}$ & D 445 & 10.7 \\
\hline Viscosity, cSt @ $100^{\circ} \mathrm{C}$ & D 445 & 2.6 \\
\hline Viscosity Index & D 2270 & 70 \\
\hline GC Distillation, $\%$ Off @ $700^{\circ} \mathrm{F}$ & D 2887E & 95 \\
\hline Color, ASTM & D 1500 & L 0.5 \\
\hline Color & D 156 & Clear, bright \\
\hline Flash Point, $\mathrm{COC}^{\circ}{ }^{\circ} \mathrm{F}$ & D 92 & 347 \\
\hline${ }^{\circ} \mathrm{C}$ & & 175 \\
\hline Pour Point, ${ }^{\circ} \mathrm{F}$ & D 97 & -27 \\
\hline${ }^{\circ} \mathrm{C}$ & & -33 \\
\hline Sulfur, Wt. $\%$ & D 3120 & $<10$ ppm \\
\hline \multicolumn{3}{|l|}{ Chemical Composition, Vol. \% } \\
\hline \multicolumn{3}{|l|}{ HPLC and UV, $W t \%$} \\
\hline Saturated Hydrocarbons & & $>99$ \\
\hline Unsaturated Hydrocarbons & & $<1$ \\
\hline & & \\
\hline & & \\
\hline & & 9-Jan-07 \\
\hline
\end{tabular}

The values shown here are representative of current production.

Some are controlled by manufacturing specifications, while others are not. All may vary within modest ranges. 